\title{
Análisis espacial de un territorio altomedieval: Nendos (La Coruña)
}

\author{
José Carlos Sánchez Pardo *
}

\begin{abstract}
RESUMEN
La combinación de Sistemas de Información Geográfica y técnicas de análisis espacial en arqueología territorial permiten profundizar en el conocimiento de las estructuras de poblamiento a lo largo de la historia y observar relaciones y tendencias -no datos absolutos- inaprehensibles de forma directa y visual. Aplicando esta metodología al estudio de un territorio altomedieval del noroeste de Galicia, a través de una perspectiva diacrónica y mediante la integración de diversos tipos de fuentes, se puede observar una evolución continua y sin rupturas de las estructuras de poblamiento desde la Antigüedad, especialmente a partir de modelos tardorromanos, hasta la Plena Edad Media, en un proceso en el que las aldeas o "villae" y las iglesias son los elementos clave en la articulación territorial.
\end{abstract}

PALABRAS CLAVE: Territorio, poblamiento, S.I.G., análisis espacial, villa, parroquia.

\section{INTRODUCCIÓN}

Hasta hace relativamente poco tiempo, la vida de la inmensa parte de los hombres y mujeres estaba intrínsecamente unida al medio natural. Esta relación no se basaba simplemente en vínculos físicos y económicos, sino también en intensos lazos simbólicos y mentales traducidos en un nivel de conocimiento y per-

\begin{abstract}
The integrated use of Geographic Information Systems and spatial analysis methods in territorial archaeology helps us to improve the knowledge of settlement structures along history and to observe relationships and tendencies -not accurate data- unnoticeable in a direct and visual way. Applying this methodology to the study of an early medieval territory in the northwest of Galicia, with a diachronic perspective and by means of the combination of diverse types of sources, we can observe a continuous evolution without breakages of the settlement structures from the Antiquity, especially from late roman patterns, until XIllth century, in a process in wich villages and churches are the main elements in the territorial articulation.
\end{abstract}

KEY WORDS: Territory, settlement, G.I.S., spatial analysis, village, parish.

cepción del territorio amplio y profundo. Es por ello que los estudios territoriales suponen una aportación mucho más importante de lo que podría parecer en un principio para comprender mejor el mundo rural a lo largo de la historia, especialmente en el caso de los siglos medievales. En este sentido el territorio se debe considerar como la unión o el resultado del medio físico y la presencia humana en él,

* CSIC-Escuela Española de Historia y Arqueología en Roma. Via di Torre Argentina 18, 00 I86, Roma.

I Este trabajo constituye una síntesis parcial de la memoria presentada por el autor para la obtención del DEA en Historia Medieval por la Universidad de Santiago en Septiembre del 2004 bajo la dirección del Prof. J. M. Andrade Cernadas y ha sido realizado dentro del Área de Arqueología Medieval de la Universidad de Siena, especialmente gracias a las explicaciones y ayuda del Prof. G. Macchi y el Laboratorio de Análisis Espacial e Informática Aplicada a la Arqueología, quienes han desarrollado parte de las metodologías aquí presentadas. 
es decir, el espacio antropizado y organizado. $Y$ en el momento en que consideramos la apropiación mental del espacio estamos hablando ya de paisaje; y su estudio a lo largo del tiempo constituye el objetivo de la llamada arqueología del paisaje, que pretende trascender y abstraer los meros datos materiales para tratar de comprender la articulación del espacio en el que el hombre vive a lo largo del tiempo. Para acercarse a esta comprensión en sentido amplio del paisaje es necesario adoptar una metodología interdisciplinar en la que deben colaborar áreas como la geografía, la historia, la estadística o las ciencias naturales; a la vez que se hace indispensable establecer una perspectiva diacrónica, que analice la evolución de esa organización espacial no en uno o varios momentos determinados, sino a lo largo de los siglos, sin establecer cortes artificiales con periodizaciones preestablecidas a procesos que continúan y se extienden en el llamado tiempo largo.

Por otro lado, en los últimos años los vertiginosos progresos de la informática han supuesto una verdadera revolución en el estudio del territorio. Estos avances se han plasmado principalmente en los llamados Sistemas de Información Geográfica (S.I.G.) ${ }^{2}$, programas que permiten representar, gestionar, relacionar, transformar y crear todo tipo de datos representados en el espacio. Sin embargo, aunque el empleo de Sistemas de Información Geográfica en investigaciones históricas y arqueológicas territoriales ha aumentado notablemente en los últimos años, es muy frecuente comprobar que su uso se reduce en general a la simple acumulación de datos, a un mero contenedor espacial, mientras que la interpretación se lleva a cabo de forma visual, y por ello, muchas veces con fuertes componentes subjetivistas.

En este sentido y muy en relación con los SIG, el análisis espacial constituye una metodología fundamental en el estudio de los datos representados en el espacio, permitiendo obtener una serie de esenciales informaciones sobre la estructura interna de los mismos que escapan a la simple vista, con frecuencia subjetiva y errónea. El análisis espacial nace en el campo de la estadística pero sus aplicaciones se extienden a muchos ámbitos, y recientemente, su combinación con medios informáticos y especialmente los Sistemas de Información Geográfica, han potenciado enormemente sus posibilidades. También en el estudio de la historia, y especialmente en el conocimiento del territorio a lo largo del tiempo, los Sistemas de Información Geográfica y los métodos de análisis espacial pueden constituir una herramienta de enorme valor. En países como EEUU, Inglaterra o Alemania hace ya años que se utilizan con grandes resultados, especialmente en áreas como la prehistoria. Sin embargo, se trata de dos aspectos muy poco desarrollados hasta ahora en el estudio de la Edad Media en España, dada sobre todo la falta de formación y conocimientos de los humanistas en estas jóvenes disciplinas. Y si entramos en el ámbito gallego, comprobamos que su presencia es prácticamente nula, al igual que algunas disciplinas que les debían servir de base como sería la arqueología medieval.

Aunque en los últimos años la llamada Arqueología Espacial, que tuvo su apogeo en los años 70-80, y el uso de técnicas cuantitativas han sido abandonados en favor de una visión más amplia: la Arqueología del Paisaje, nacida dentro del giro postprocesual y de las críticas a los intentos de reducir la realidad a simples números y estadísticas (ESCALONA; ALFONSO; REYES, en prensa), consideramos que, siendo siempre conscientes de la inmensa complejidad de la historia, no se debe rechazar de golpe toda la potencialidad de los métodos de análisis espacial en historia, entendidos no como reveladores de leyes o axiomas sino como posibles indicadores de tendencias, valores medios y aproximativos que nos ayuden a entender e

\footnotetext{
2 A lo largo de este trabajo distinguiremos, como actualmente es frecuente, entre SIG, es decir, los Sistema de Información Geográfica como metodología general de trabajo, y el GIS (Geografic Information System) o programa de software concreto en el que se trabaja.
} 
interpretar mejor procesos históricos (MACCHI JÁNICA, 200 I: pp. 6I-65).

En el trabajo que sigue intentaremos precisamente combinar los aspectos que acabamos de apuntar, es decir, el estudio diacrónico de un territorio entre la Tardoantigüedad y la Plena Edad Media, como ejemplo de evolución y articulación espacial en la Galicia medieval, y la explicación de las posibilidades que en él puede ofrecer un Sistema de Información Geográfica, especialmente en el ámbito del análisis espacial. Por ello, la idea general que recorre las siguientes páginas no es la de saturar y aburrir con datos técnicos de importancia relativa, sino la de presentar una metodología que consideramos interesante y necesaria en los estudios territoriales, tanto por sus posibilidades en la investigación como por el componente de objetividad que puede introducir en temas a menudo hipotéticos o subjetivos.

Concretamente nos centraremos en un territorio bien individualizado en las fuentes altomedievales gallegas, como es el territorio de Nendos o Nemitos, en la provincia coruñesa, del cual trataremos de analizar los aspectos principales de su organización espacial entre la Antigüedad y la Plena Edad Media, atendiendo especialmente a la configuración y cambios en el modelo de hábitat de cada época (poblamiento castreño, asentamientos romanos, comunidades rurales altomedievales, "villae" medievales) a través de todas las fuentes disponibles sobre este territorio.

\section{El territorio de estudio}

El objeto de nuestro estudio, el territorio de Nendos, constituye un espacio individualizado, conocido y delimitado durante la Alta y Plena Edad Media en Galicia. Hay que recordar que el "territorio" en estos siglos no es un término genérico o abstracto sino que supone todo un nivel concreto de organización espacial fundamental en Galicia, constituido por un entorno socionatural homogéneo e individualizado a través de los accidentes naturales del terreno, especialmente los valles. Los territorios serían los antecedentes de las actuales comarcas y en muchas ocasiones continuaban la red de articulación territorial antigua (BALIÑAS, 1992: pp. 318-330), como ocurre en nuestro caso.

Geográficamente, Nendos se halla en la costa noroeste de Galicia, en la provincia de A Coruña (Figura I) y comprende, por el litoral, el espacio natural de las rías de Coruña y Betanzos, y hacia el interior, los valles de los ríos Mero, Mendo y Mandeo. Actualmente esto coincide aproximadamente con los términos municipales de Oleiros, Sada, Cambre, Bergondo, Betanzos, Oza dos Ríos, Abegondo, Cesuras y parte de los de Carral, Paderne, Coirós, Irixoa y Aranga. El territorio de Nendos ocuparía una superficie aproximada de $558 \mathrm{~km}^{2}$ en el momento de mayor expansión de sus límites, que formarían un perímetro de cerca de $140 \mathrm{~km}$ de longitud. A nivel físico, este territorio constituye una unidad caracterizada por relieves suaves y constantes (Figura I0), que oscilan entre los 10-100 metros de altura en la zona costera, hasta los 300-450 metros en la zona interior de Cesuras y Aranga. Igualmente esta zona presenta una tupida red hidrográfica protagonizada por el Mero y el Mandeo, que crean en su interfluvio un espacio fértil para la agricultura (especialmente el primero, que forma un valle más abierto y llano que el del Mandeo). El clima en este territorio cercano al Atlántico es de tipo oceánico con temperaturas suaves y precipitaciones abundantes y uniformes a lo largo del año.

Esta unidad física dio lugar a lo largo del tiempo a una unidad histórica. Actualmente constituye uno de los territorios más densamente poblados de Galicia (BOUHIER, 200I: pp. 99138), con una tupida red de pequeños y medianos núcleos de poblamiento distribuidos prácticamente por toda su extensión. Durante la Antigüedad, Nendos debió formar parte del llamado Golfo Ártabro, espacio que comprendía las rías de Ferrol, Ares, Betanzos y Coruña, y donde se asentaban, según autores clásicos como Plinio y Estrabón, la tribu de los ártabros. Probablemente nuestro territorio conformaba ya en esta época una división espacial individualizada dentro del Golfo Ártabro, dado que el propio topónimo de Nemitos podría indicar un origen indígena prerromano. De todos 
modos, es a partir de la Alta Edad Media cuando tenemos noticias exactas de su existencia, concretamente en el año 842, cuando se cita por vez primera en un documento del Tumbo del monasterio de Sobrado (LOSCERTALES, 1976: doc. 34) ${ }^{3}$ con el nombre de Nemitos. Sin embargo, la documentación no ofrece datos exactos sobre sus límites territoriales, aunque sí algunas referencias en menciones como la de un documento del Tumbo A de Santiago de Compostela, datado en el año 1020, donde se dice: "Monasterio Piavela, territorio Nemitos, inter duo flumina Mandeo et Mero" (LUCAS ÁLVAREZ, 1998: doc. 62), lo que nos da ya idea de su ubicación originaria en el espacio comprendido entre ambos ríos. Sin embargo, como veremos a lo largo de este trabajo, el territorio medieval no posee unos límites o fronteras estrictas como los términos administrativos contemporáneos, lo cual no implica en absoluto que no sea un espacio bien conocido e individualizado para los hombres y mujeres de esta época. Por otro lado, el territorio originario de Nemitos irá ampliándose a lo largo de la Edad Media, según se observa en la documentación, que a partir del siglo XI incluye en este territorio núcleos de población fuera de aquellos límites altomedievales. Sin embargo, en un estudio espacial y territorial como pretende ser este, es necesario establecer unos límites precisos al área de análisis, por lo que se han delimitado unas fronteras más o menos ajustadas a los datos que hemos podido obtener sobre este territorio histórico, tal y como se puede observar en el mapa inferior. Estos límites coinciden aproximadamente con los que López Alsina traza para el conjunto de los territorios altomedievales de la diócesis de Iria (LÓPEZ ALSINA, 1988). Por otro lado, el territorio altomedieval de Nemitos pasará a llamarse Nendos a partir de los siglos XII-XIII, convirtiéndose definitivamente en una división eclesiástica de la diócesis de Santiago de Compostela que sin apenas cambios ha pervivido hasta nuestros días.
Por tanto, nos encontramos ante un espacio con características específicas e individualizadas tanto a nivel físico como histórico, razones por las que puede constituir un área de especial interés para analizar las características y evolución de la articulación territorial a lo largo de la Tardoantigüedad, la Alta y Plena Edad Media en Galicia.

\section{FUENTES, DATOS Y CONSTRUCCIÓN DE UN SISTEMA DE INFORMACIÓN GEOGRÁFICA}

Siguiendo el carácter metodológico que hemos propuesto para estas páginas, vamos a explicar brevemente los pasos seguidos en esta investigación para crear un Sistema de Información Geográfica de un territorio galaico medieval. Este SIG representa la base desde la cual podremos posteriormente gestionar, transformar y analizar todos los datos e investigaciones posteriores. Por ello es de fundamental importancia estudiar, elaborar e implementar adecuadamente todos los elementos que lo constituirán.

\section{Fuentes y su problemática}

Tras delimitar la zona, cronología y objetivos de estudio, se ha realizado una búsqueda lo más exhaustiva posible de toda información histórica y arqueológica disponible relativa al territorio de Nendos ${ }^{4}$. A pesar de las muchas carencias debidas a la naturaleza de las fuentes históricas existentes, se puede considerar que el análisis y vaciado de las fuentes empleadas constituye una base suficientemente amplia y representativa para realizar un acercamiento a la organización territorial de Nendos entre la Tardoantigüedad y la Plena Edad Media. Estas fuentes principales de nuestro trabajo se pueden clasificar en 4 tipos:

\footnotetext{
3 Esta primera mención adelanta 68 años la considerada por C. Baliñas en la obra arriba citada.

4 En nuestra tesis doctoral estamos trabajando en la recopilación y análisis de nuevos datos documentales, arqueológicos y toponímicos de este y otros territorios gallegos, lo cual permitirá ampliar y completar los resultados aquí expuestos.
} 
- Fuentes documentales: Para este trabajo se ha consultado y vaciado la documentación de los Tumbos de los monasterios de Sobrado de los Monjes (La Coruña) (LOSCERTALES, 1976), San Julián de Samos (Lugo) (LUCAS ALVAREZ, 1986), San Salvador de Celanova (Orense) (ANDRADE CERNADAS, 1995), San Juan de Caaveiro (La Coruña) (FERNÁNDEZ DE VIANA Y VIEITES; GONZÁLEZ BALASCH; CASTRO ÁLVAREZ, 1999), así como la documentación del Tumbo A de la Catedral de Santiago de Compostela (LUCAS ÁLVAREZ, 1998).

En esta documentación hallamos numerosas menciones a entidades del poblamiento en Nendos a partir del siglo IX. Sin embargo todas estas fuentes textuales presentan también una serie de problemas que debemos tener en cuenta antes de comenzar nuestro estudio, ya que este tipo de documentación contiene datos escasa y difícilmente cuantificables, parciales y desiguales en su información y de procedencia casi exclusivamente monástica, de modo que la realidad territorial descrita en ellos corresponde solamente a la perspectiva e intereses de los monjes (PALLARES MÉNDEZ, 1979: pp. $X X V-X X X$.). Por otro lado hay que tener en cuenta que un Tumbo es una recopilación y selección de documentos en épocas posteriores a su redacción original, lo que significa que solo han llegado hasta nosotros aquellos que presentaban algún valor o interés para el monasterio en el momento en que se realizó la recopilación. Además de estas lagunas de datos históricos relevantes para nuestro estudio, encontramos otros problemas bien conocidos por los medievalistas relativos a la localización de los topónimos que aparecen en la documentación, al desconocimiento de su cronología, o a la autenticidad del documento.

- Fuentes arqueológicas: En un estudio territorial como el que pretendemos realizar, los datos arqueológicos o materiales se constituirían en elementos fundamentales, especialmente aquellos derivados de prospecciones y teledetección. Desgraciadamente nos encontramos con que apenas existen datos publicados o accesibles sobre actividades de arqueología medieval, no solo en esta zona, sino en todo el ámbito gallego. Ello nos obliga a depender únicamente de algunas escasas, y por lo general antiguas y breves, publicaciones de resultados de excavaciones, prospecciones y estudios de arqueología medieval en la provincia coruñesa (CASTILLO, 1923; CHAMOSO, 1953, 1965, 1966, 1967, 1971, 1999; FARIÑA BUSTO; SUÁREZ OTERO, 1997; LUENGO MARTÍNEZ, 1950; NUÑEZ RODRIGUEZ, 1977a, 1977b; PALLARES MÉNDEZ; PUENTE MÍGUEZ, 1981; VALDÉS BLANCO-RAJOY, 1996). Además, la mayoría de estos estudios se centran en temas muy concretos, como el de las necrópolis altomedievales, permaneciendo prácticamente sin analizar aspectos como el hábitat, las estructuras defensivas, vida material... de los siglos medievales en Galicia. Por todo ello, intentaremos suplir en la medida de lo posible estas carencias con un mayor recurso a las fuentes escritas y toponímicas, no sin antes volver a reclamar la urgente necesidad de desarrollar la arqueología medieval en Galicia.

Por otro lado, como ya hemos comentado, en este trabajo pretendemos adoptar una perspectiva diacrónica, esencial para un estudio de arqueología territorial (CAMBI; TERRENATO, 1994), por lo que debemos utilizar también datos de época antigua. Para esta etapa existe una mayor cantidad de información arqueológica disponible, pero todavía siguen existiendo muchas e importantes lagunas que hacen necesarios nuevos y más profundos estudios. En este trabajo hemos recurrido a algunas publicaciones y catálogos específicos sobre arqueología del Golfo Ártabro (NAVEIRO LÓPEZ, I994; PÉREZ LOSADA, 2002), de los que hemos tomado la mayor parte de los datos sobre poblamiento castreño y romano en el territorio de Nendos.

- Fuentes cartográficas: En un estudio histórico del territorio, la cartografía no supone únicamente un instrumento o medio de trabajo, en el que localizar y analizar los datos, sino también una fuente de información his- 
tórica y arqueológica esencial de la que podemos extraer nuevos y posibles datos, en base a la orografía, comunicaciones, hidrografía... En esta investigación hemos empleado mapas correspondientes a nuestro territorio (es decir, aquellos que cubren los actuales municipios de Oleiros, Sada, Betanzos, Bergondo, Cambre, Oza dos Ríos, Abegondo, Coirós, Carral, Paderne, Irixoa, Cesuras y Aranga) procedentes de la cartografía 1:25000 del Instituto Nacional de Información Geográica, la cartografía digital 1:5000 de Galicia y el mapa de Parroquias de Galicia a escala 1:200000 elaborado por el SITGA.

- Fuentes toponímicas: A pesar de toda una serie de limitaciones y precauciones que se deben tener siempre en cuenta al usar este tipo de datos, la toponimia de un lugar o territorio puede ofrecer una importante información histórica, especialmente con la combinación y corroboración de otras fuentes. En este estudio se ha recurrido a listados y estudios de topónimos de nuestra zona de estudio (MORALEJO LASSO, 1977) ${ }^{5}$ para intentar extraer una serie de datos, que sin dejar de ser hipotéticos, pueden ayudar a comprender mejor las pautas de poblamiento y organización del espacio entre la Antigüedad y la Plena Edad Media.

\section{Búsqueda y clasificación de los datos}

A partir de todas estas fuentes se ha logrado reunir, localizar y clasificar de la forma más exhaustiva posible toda una serie de datos referidos a diversas entidades del poblamiento en la evolución histórica del territorio de Nendos (Figura 2). Dicha información se ha organizado en bases de datos para a continuación ser introducida en el programa GIS. Hay que señalar que la clasificación o encuadramiento del dato en unos parámetros, clases o criterios deter- minados, como implica una base de datos, supone en ocasiones la pérdida de "calidad" o precisión individual de la información, pero a cambio permite ganar en el ámbito de la cuantificación y análisis global. De esta forma, se han establecido las siguientes categorías de datos recopilados:

- Poblamiento medieval. Villae, entidades secundarias y entidades eclesiásticas: Estos datos se han obtenido y localizado a partir del vaciado de la documentación anteriormente citada a través de un proceso de búsquedas jerarquizadas en el índice toponímico de cada tumbo y recurriendo constantemente a la cartografía de la zona. No obstante, en algunas ocasiones no ha sido posible conocer la localización exacta de ciertos lugares, dado que han desaparecido como poblaciones o simplemente han cambiado su nombre.

En cuanto a los datos en sí, tras observar las características de las menciones, hemos decidido establecer tres grandes clases o grupos de entidades de poblamiento medieval en el territorio de Nendos según la documentación: villae o "villae" ${ }^{6}$, entidades "secundarias" y "entidades eclesiásticas". Cada uno de estos conjuntos de entidades se ha organizado como una base de datos específica.

La villa es el tipo de entidad de poblamiento más mencionada en los documentos y que constituye el núcleo fundamental de la organización del espacio medieval gallego (Figura 3). Según se desprende de la documentación la villa sería un territorio de habitación y explotación agraria centrado por una aldea o grupo de casas que se situaba dentro de unos límites muy precisos y se organiza en tres niveles: un núcleo habitacional y de huertos, una zona de explotación agrícola y una zona de terrenos incultos o bosque

\footnotetext{
5 También ha sido de gran utilidad el nomenclator del servicio de Correos del año 1940.

6 En adelante al referirnos al plural de "villa" usaremos el término latino "villae" en vez del español "villas" para evitar posibles confusiones con los núcleos modernos de carácter semiurbano.
} 
(V.AA., 1988: pp. 102-103; ISLA FREZ, 1998, 200।; ANDRADE CERNADAS, 1996; PALLARES MÉNDEZ; PORTELA SILVA, 1997, 1998). En total se han podido reunir y clasificar como villae un total de I I I entidades, cuya primera mención documental va desde el año 842 hasta inicios del siglo XIII.

Bajo el nombre de "entidades secundarias" hemos agrupado todas aquellas referencias a elementos de poblamiento del territorio de Nendos que no son villae, ya que poseen un menor tamaño e importancia así como una función diferente, aunque generalmente se integren dentro del espacio de una villa. Dichas entidades serían: agros, casales, fuentes, lugares, marcos, pumares y villares (Figura 3). En total se han podido reunir 55 entidades secundarias, con fechas iniciales que van desde el año 872 hasta el 1242.

Las entidades eclesiásticas corresponderían a todas las instituciones religiosas del territorio que aparecen en la documentación de los cinco tumbos documentales consultados. Se trata principalmente de iglesias y monasterios, aunque no resulta sencillo distinguir siempre bien entre ambos conceptos ya que con frecuencia en la documentación se denomina a una misma entidad a veces como iglesia y otras como monasterio. Por ello hemos decidido clasificar las menciones a entidades eclesiásticas en tres tipos: iglesia (edificio destinado al culto religioso público), monasterio (cenobio o comunidad de monjes dedicados al trabajo y la oración) e iglesia-monasterio (reunión de ambas instituciones religiosas en un mismo lugar o entidad).

En todos estos datos sobre entidades de poblamiento medieval llama enseguida la atención su alta tasa de continuidad o pervivencia hasta el día de hoy, ya que la gran mayoría de estas entidades, especialmente las iglesias, los monasterios y las villae, existen actualmente (Figura 4), como veremos más adelante, lo cual facilita mucho su localización y estudio.
Como acabamos de comentar, cada uno de estos tres grupos constituye una base de datos diferente, en la que se recogen los nombres de las entidades, referencias documentales, fechas de las menciones, tipo de entidad, localización actual, nivel de fiabilidad de dicha localización (alto, medio o bajo), pervivencia en nuestros días, fecha de la primera mención (campo cuya finalidad es la de permitir búsquedas cronológicas, como fecha mínima segura o datación “antequem"), etc. Una vez localizadas todas las menciones se observa que en el total de 197 entidades de poblamiento medieval documentadas existe una tendencia a una mayor concentración en la zona central y centro-sur del territorio de Nendos, quedando el Norte, es decir, la costa, el suroeste $y$, en menor medida, el sureste, más vacíos de poblamiento (Figura 2).

- Poblamiento castreño: Para recopilar este conjunto de datos sobre castros conocidos en el territorio de estudio, se ha recurrido principalmente a la cartografía y a publicaciones con referencias a arqueología del Golfo Ártabro en época antigua (NAVEIRO LÓPEZ, 1994; PÉREZ LOSADA, 2002), territorio del que, como sabemos, Nendos es en parte heredero y continuador en época medieval. En total se han podido localizar 78 castros en esta zona, que se han clasificado en una base de datos con campos relativos al nombre, la tipología del castro, localización, etc. Estos castros parecen distribuirse prácticamente por todo el territorio de estudio, aunque de nuevo, observamos una menor concentración en la zona suroeste y sureste $y$, en cambio, una mayor densidad en la costa

- Indicadores de época y cultura romana o galaicorromana: Se ha adoptado esta denominación tan genérica para encuadrar las escasas e incompletas informaciones sobre diversos restos materiales adscribibles cronológica y/o culturalmente al mundo romano o galaicorromano. Los datos proceden, al igual que en el apartado anterior, del listado ofrecido por J. Naveiro López y F. Pérez 
Losada. La falta de prospecciones y excavaciones sobre este tema en el territorio de nuestro estudio solo ha permitido reunir, localizar y clasificar en una base de datos un escaso número de datos: 20 yacimientos, de muchos de los cuales apenas se conoce su función. En general se puede hablar de algunos restos de actividad minera, especialmente en la zona de Paleo-Carral, para el aprovechamiento de los recursos auríferos, algunos hallazgos más bien descontextualizados de aras votivas y placas funerarias, y diversas estructuras de habitación o de actividades productivas (agricultura, salazón, horno cerámico...). Su distribución en el mapa de Nendos parece seguir un cierto alineamiento o distancia común entre ellos, y se hallan por lo general también cerca de poblados castreños (Figura 2).

- Necrópolis altomedievales: se trata de seis restos funerarios de interpretación bastante controvertida. Tradicionalmente arqueólogos como Chamoso Lamas consideraban este tipo de necrópolis como "suevas" o "germánicas". Sin embargo nuevas revisiones sobre este tema advierten que estos sarcófagos no pueden adscribirse tan sencillamente a una época determinada a partir de unos "fósiles directores" como podría ser la decoración en estola, sino que habría que analizar cada caso de forma independiente y atendiendo a su contextualización particular, por lo que son necesarias todavía nuevas investigaciones que avancen y profundicen más que la simple descripción y clasificación de las lajas, sarcófagos o decoraciones, enmarcándolas en el contexto más amplio que supone cada necrópolis (con su evolución y la problemática de remociones, reutilizaciones...) y en el de la sociedad que las creó (clase social a la pertenecen, simbología, ritual funerario...). Por todo ello, de momento no se puede precisar una cronología más precisa que la "altomedieval" (en general entre los siglos V-XI), para los seis restos funerarios de este tipo que conocemos en nuestro territorio y que se concentran en una única zona, la parte centrooriental de Nendos.
- Topónimos acabados en "-obre" y afines: Este conjunto de topónimos constituye un caso peculiar y de gran interés histórico, especialmente en lo que se refiere al territorio de Nendos, razón por la que han sido objeto de diversos estudios entre los que destacan los del Padre Sarmiento, R. Menéndez Pidal o más recientemente A. Moralejo, a quien seguimos en este tema (MORALEJO LASSO, 1977: pp. 49-83). Se trata de una serie de nombres de lugar y poblaciones caracterizados por presentar el sufijo final "-obre" o sus derivados "-obe", "-ove", "-abre", "-ebre" y "-ubre", y por concentrarse de forma casi exclusiva en la provincia coruñesa, especialmente en torno al antiguo Golfo Ártabro, es decir, el entorno de las rías de Coruña, Betanzos, Ares y Ferrol, donde se hallan casi la mitad de todos los topónimos de este tipo conocidos. Concretamente los I5 topónimos con terminación en "-obre" $y$ afines que existen en Nendos se encuentran concentrados principalmente en la zona central del territorio, y en general, muy cerca de poblamientos castreños.

La mayoría de las investigaciones suponen un origen prerromano para estos topónimos, así como una relación fonética con el sufijo céltico "-briga" ("ciudad o fortificación en altura"). Según Menéndez Pidal y A. Moralejo, estos topónimos delimitarían el territorio de una misma tribu o grupo de población indígena, y se puede pensar que la mayor frecuencia de los mismos sea un indicio de mayor densidad de población en la Edad del Hierro. A pesar de la precaución con la que se deben tratar los datos e hipótesis toponímicas, hemos considerado interesante incluir esta serie de nombres de lugares en nuestro estudio, especialmente por ser tan específicos y característicos del territorio que estamos analizando, para intentar comprobar y ampliar en la medida de lo posible el simple dato filológico.

- Topónimos sobre castillos: Al igual que en gran parte de la Península Ibérica también abundan en el territorio de Nendos los topónimos que hacen referencia a castillos: $\bigcirc$ Cas- 
telo, A Torres, Castelos... De nuevo es muy importante tener en cuenta las limitaciones del dato meramente toponímico, que en este caso no puede ser considerado más que un posible o hipotético indicio de la existencia de un castillo o estructura fortificada en ese lugar determinado en algún momento de su historia (no necesariamente medieval), pero nunca una evidencia absoluta. No obstante, y siendo siempre conscientes del mero carácter hipotético de estos datos, intentaremos conocer si existe algún patrón de distribución de dichos topónimos y hasta que grado podrían ponerse en relación con posibles fortificaciones o estructuras defensivas de época alto y pleno medieval en esta zona, así como con poblados castreños, con los que no pocas veces se asocia este topónimo. Su distribución en el territorio de Nendos se concentra principalmente en la costa norte, y en el sur del territorio. En menor medida, estos topónimos se hallan en los extremos este y oeste del territorio, mientras que el centro aparece prácticamente vacío de estos topónimos.

- Parroquias actuales: A partir del mapa y listado de parroquias elaborado por el SITGA (PRECEDO LEDO; GALLEGO PRIEGO, 200 I), hemos decidido incluir en el Sistema de Información Geográfica, el elenco de parroquias y sus territorios existentes actualmente en el territorio de Nendos. Como ya hemos indicado, la parroquia y la red parroquial constituye hoy en día una de las organizaciones del espacio más antiguas, fuertes y específicas que existen en Galicia (RODRÍGUEZ CAMPOS, 1991: pp. 158-199; FARIÑA TOJO, 1980; FARIÑA JAMARDO, 1996) y puede considerarse en ciertos aspectos el reflejo de una organización territorial que hunde sus raíces en el periodo altomedieval. Desde esta perspectiva de reflejo, siempre limitado, de una organización espacial tradicional y de origen básicamente medieval, utilizaremos en este análisis los datos sobre parroquias y sus límites territoriales actuales para ponerlos en relación con los datos espaciales de época antigua y medieval que poseemos en Nendos y tratar de dilucidar posibles paralelismos y perviven- cias. En general esta red parroquial se distribuye de forma regular y bastante homogénea por todo el territorio. De nuevo, la zona sureste, y en menor medida, la zona suroeste, parecen presentar una menor densidad de parroquias, y en consecuencia unos territorios parroquiales más grandes. En general, y solo a simple vista, parece existir una cierta correspondencia entre el patrón de distribución de esta red de parroquias actuales y el de las entidades de poblamiento medievales que hemos comentado anteriormente.

- Datos cartográficos: En nuestro caso, hemos utilizado como base la cartografía de Galicia a escala 1:5000 y hemos "separado" o creado a partir de ella una serie de datos geográficos que nos interesan especialmente. En primer lugar, los límites del propio territorio, aunque como ya hemos comentado para este caso, no siempre es sencillo establecer unos límites o fronteras precisas en territorios y épocas en que no existe una delimitación clara y estricta de los mismos. Por ello hemos decidido establecer unos límites relativos y aproximados según la información de la documentación, para el territorio de Nendos (entonces aun llamado Nemitos) en torno al siglo $X$, y otros en torno al siglo XIII. Otros datos cartográficos fundamentales para nuestro análisis son la hidrografía, los límites de municipios actuales, los microtopónimos, las curvas de nivel y la línea de la costa.

\section{ANÁLISIS ESPACIAL}

A partir de todos estos datos se pueden realizar diferentes estudios e interpretaciones. En este trabajo nos centraremos solamente, tal y como propusimos al inicio, en una serie de análisis de carácter espacial, que a pesar de su simplicidad, consideramos que pueden ayudarnos a entender las características y evolución diacrónica de la red de poblamiento en el territorio de Nendos.

El análisis espacial estudia mediante técnicas y modelos matemáticos y estadísticos la 
dimensión espacial de la información; lo cual, aplicado a la geografía, permite obtener datos imperceptibles para el ojo humano y sin embargo fundamentales para entender la articulación espacial de un territorio ?.

Dada la complejidad que muchas veces alcanza el estudio de los datos espaciales, debido principalmente al carácter cuantitativo de esta disciplina, la informática, y de forma muy notoria, los programas GIS, se han convertido en herramientas casi indispensables en el análisis espacial, que agilizan, simplifican y realmente multiplican enormemente las posibilidades de esta disciplina. Sin embargo, a la hora de aplicar el análisis espacial a la historia, debe ser el historiador y no el matemático o informático quien desarrolle estos análisis, pues el ámbito estudiado es justamente el suyo, y solo el historiador puede decidir en que modo puede ser interesante usar las posibilidades de esta metodología y cómo se deben interpretar los resultados. De ahí la importancia de que los historiadores conozcan y apliquen esta disciplina.

En base a todo esto, en las siguientes páginas intentaremos explicar y desarrollar una serie de análisis espaciales de los datos reunidos anteriormente sobre el territorio de Nendos entre la Antigüedad y la Plena Edad Media. Sin embargo, no nos ocuparemos ahora de la interpretación global e histórica de los resultados, sino que ese será el objetivo de la última parte del trabajo. Por otro lado, además del uso del GIS como herramienta fundamental en todo este estudio, emplearemos también el programa Spatial Analysis Utilities (SAU) desarrollado en el Laboratorio de Informática aplicada a la Arqueología Medieval de la Universidad de Siena por el equipo del profesor Giancarlo Macchi. Este programa permite realizar distintos análisis espaciales de forma muy sencilla, rápida y eficaz, convirtiéndose en una herramienta de enorme utilidad en un estudio territorial, por sí sola o en combinación con un GIS, como veremos a lo largo de este capítulo.
Antes de comenzar esta serie de análisis espaciales, debemos señalar con énfasis una premisa fundamental en todos ellos. Como ya hemos comentado, los datos que hemos podido reunir a través de las escasas, incompletas y parciales fuentes disponibles no pueden reflejar en absoluto la realidad del poblamiento y organización del espacio en el territorio de Nendos entre la Antigüedad y la Plena Edad Media, sino solamente y no sin problemas, algunas de las partes y características que lo definían. Es por ello que los resultados que obtendremos en los siguientes análisis no se pueden considerar bajo ningún concepto, absolutos o completos. No obstante, teniendo en cuenta que en estadística, cuanto mayor es el universo de datos, más fiable y aproximado es el resultado, podemos interpretar los resultados como tendencias, indicios, valores medios o aproximativos, a partir de los cuales, siempre conscientes de que la compleja realidad no se puede reducir a cifras, tratar de acercarnos de forma un poco más completa al conocimiento de la articulación del espacio histórico.

\section{Análisis de cambios en las densidades según la situación geográfica}

Una de las principales posibilidades de un Sistema de Información Geográfica es la de permitir búsquedas según la localización de los datos en el espacio. Gracias a esta función se pueden realizar investigaciones de gran utilidad para el conocimiento de la evolución, ordenamiento, influencias y características comunes de una serie de datos distribuidos en un área determinada.

En base a este principio de búsqueda a través de criterios espaciales, vamos a realizar un tipo de análisis de distribución de los datos que poseemos en el territorio medieval de Nendos según la mayor o menor cercanía a otras entidades y factores determinados, con el obje-

\footnotetext{
7 En la elaboración de esta breve introducción al análisis espacial nos basamos en las explicaciones de los profesores G. Macchi y M. Valenti del Departamento de Arqueología Medieval de la Universidad de Siena.
} 
tivo de intentar discernir las causas de su estructura y organización, o dicho de otro modo, comprobar si hay variaciones en la densidad de un tipo de poblamiento o distribución en función de su posición espacial. Para estudiar estos cambios de densidad según la cercanía a diversos factores, hemos construido unos gráficos o histogramas que ponen en relación las variables densidad y distancia (Figuras I I, 12 y 13). Estos gráficos no son más que el reflejo numérico de una serie de anillos concéntricos de igual radio establecidos en el GIS entorno a los elementos a estudiar, y del cálculo, mediante una serie de procesos en el propio programa, de los cambios en la densidad de otras entidades del territorio según estén más lejos o más cerca de aquellos elementos ${ }^{8}$.

A continuación presentaremos de forma muy sintética, algunos de los resultados obtenidos a través de este análisis en nuestro territorio de estudio 9 . Pero antes debemos recordar nuevamente que los valores obtenidos son simplemente intervalos medios estadísticos $y$, por tanto, la función principal de este tipo de análisis no es tanto la de presentar cifras exactas como la de mostrar tendencias, características generales y desde esa perspectiva debemos analizar e interpretar estas gráficas.

\section{ANALISIS DE DENSIDADES SEGÚN LA DISTANCIA A LA RED DE CASTROS} (Figura II)

En primer lugar estudiamos la relación espacial entre los castros y los datos relativos a entidades de poblamiento medieval del territorio de Nendos, como son las villae y las "entidades eclesiásticas" en torno al año 1000 y al 1250 a través de intervalos de 500 metros. Como ya hemos comentado empleamos diferentes límites territoriales de Nendos para el año I000 que para mitad del siglo XIII, ya que este territorio crece y amplía sus límites durante esos tres siglos. En todas estas gráficas observamos una misma tendencia: una densidad de poblamiento medieval creciente y por encima del valor esperado en los primeros 1000 metros en torno al castro, alcanzándose la densidad máxima en torno a esos 1000 metros de distancia al castro. A partir de ese valor, comienza a descender, igualándose con el valor teóricamente "esperado" a los 1500 metros del castro y continuando el descenso de la densidad bajo niveles menores de los esperados a medida que aumenta la distancia al castro.

En cuanto a los restos de época romana, muestran también una clara tendencia a localizarse y concentrarse en áreas muy cercanas a los castros. De hecho, el máximo nivel de densidad de yacimientos romanos se localiza a menos de 500 metros del propio castro, y desde allí desciende rápidamente de modo que a 1200 metros la densidad de indicadores romanos se iguala con el valor teórico esperado en el caso de que no existiese influencia o relación espacial directa entre castros y yacimientos romanos. Sin embargo alrededor de los 2000 metros (insistimos que se trata de intervalos de distancia media estadísticos, es decir, aproximados, no de valores absolutos) parece denotarse un aumento de la densidad de yacimientos romanos, lo cual podría estar reflejando el proceso de abandono del hábitat castreño en altura o semialtura por un asentamiento en el valle. Esos 2 kilómetros representarían la distancia media entre el poblado castreño y el nuevo asentamiento romano. A partir de ahí desciende de nuevo el índice de densidad hasta llegar a desaparecer alrededor de los 3500 metros del castro. Hay que señalar que los picos o rebrotes repentinos que observamos al final de las gráficas, como sucede en ésta a 3500 metros, no son representativos ya que corresponden a áreas muy

8 Este tipo de análisis se puede completar y afinar con la elaboración de superficies de costes, que introducen en el análisis factores geográficos de gran importancia para comprender la articulación espacial de un territorio, como son las pendientes del terreno, las zonas intransitables... En esta dirección estamos trabajando actualmente.

9 Para no alargar ni hacer más tedioso el texto y las gráficas, haremos mención tan solo a los análisis cuyos resultados nos han parecido más indicativos o interesantes, evitando otra serie de datos estudiados que, en todo caso, sí son comentados y tenidos en cuenta en la interpretación global. 
pequeñas en las que un solo dato provoca un valor de densidad muy elevado.

Una de las gráficas más interesantes y más claras de este análisis de densidad en función de la distancia a castros, es la de los topónimos acabados en "-obre", que presentan una fortísima relación espacial con los castros de modo que la mayoría se encuentran en el propio castro o a menos de 500 metros del mismo, descendiendo a continuación a valores poco significativos hasta desaparecer a $2500 \mathrm{~m}$. del castro. Esto pone en evidencia la relación entre estos topónimos de probable origen indígena y prerromano y lugares de poblamiento antiguo como los castros, así como el alto grado de continuidad histórica en estos lugares que parecen presentar una ocupación ininterrumpida desde al menos finales de la Edad del Hierro, pasando por la etapa medieval hasta nuestros días.

En el caso de los topónimos sobre castillos, en contra de lo esperado inicialmente no ha aparecido una relación de cercanía entre el lugar donde se asentaba un castro y el topónimo "castillo", sino que más bien tienden a concentrarse entre 1500 y 2500 metros de distancia de los mismos. A pesar de la gran incertidumbre, relatividad e inexactitud del dato meramente toponímico, podemos concluir que si efectivamente el nombre de estos topónimos responde a una anterior existencia de castillos, éstos generalmente no se construirían sobre un anterior poblado castreño. Quizá esto se pueda explicar por la diferente función y emplazamiento buscado para una fortificación en la Edad Media y Moderna (lamentablemente carecemos de cualquier datos cronológico más preciso), que se situaría en lugares más altos y estratégicos que los usados para el asentamiento castreño (que, recordemos, no se situaban en zonas demasiado elevadas) con una finalidad de control y organización territorial diferente a la del castro en época antigua.

\section{ANALISIS DE DENSIDADES SEGÚN LA DISTANCIA A INDICADORES ROMANOS} (Figura 12)

Con la misma metodología realizamos otro análisis de cercanía de diversas entidades a yaci- mientos romanos o galaicorromanos, usando el mismo radio de análisis, dado que consideramos que también es el más adecuado para comprobar posibles influencias de la este tipo de poblamiento sobre otros datos históricos de Nendos.

A pesar de su escasez y problemática, los datos sobre necrópolis altomedievales reflejan aquí una tendencia bastante clara a concentrarse cerca de lugares en los que hubo algún tipo de ocupación romana, ya que se da una gran densidad de necrópolis altomedievales a menos de 500 metros de yacimientos romanos, para descender a continuación a niveles poco significativos a efectos de posibles relaciones espaciales entre ambos. Esto de nuevo nos acerca a la idea de continuidad, en este caso de uso y ocupación de ciertos asentamientos y necrópolis de época romana y tardorromana al menos durante época altomedieval.

En el caso de las entidades de poblamiento alto y pleno medievales en Nendos, es decir, villae y entidades eclesiásticas tanto en torno al año 1000 como al 1250, también observamos una nítida tendencia a situarse cerca de lugares con restos de época romana, especialmente en los datos referentes al año 1000 (debemos recordar que no hablamos de cifras absolutas sino de densidades, es decir datos divididos por $\mathrm{Km}^{2}$ ). En el caso de las villae se denota una mayor densidad cerca de los indicadores romanos, aunque no sea demasiado fuerte. Sin embargo, en el caso las entidades eclesiásticas, encontramos una clara y fuerte tendencia a concentrarse con gran densidad en o muy cerca de anteriores asentamientos romanos, a menos de 500 metros de ellos, tanto en el año 1000 como en el 1250. Quizá podemos interpretar o intentar explicar esta clara tendencia de las entidades eclesiásticas a emplazarse en o muy cerca de ocupaciones romanas teniendo en cuenta el contexto histórico de nacimiento de la organización eclesiástica en Gallaecia durante la Tardoantigüedad y Alta Edad Media, que comenzaría, se asentaría y se basaría no tanto en los antiguos asentamientos indígenas sino en las zonas más romanizadas, dada la cobertura y organización previa que el imperio, ya oficialmente cristia- 
no, brindaba a la nueva estructura religiosa; organización que con el tiempo y aunque solo sea en parte y con muchas adaptaciones, la iglesia continuaría.

En cambio, los topónimos con sufijo en "obre" y afines no ofrecen una respuesta demasiado clara a este análisis ya que, aunque la gráfica parece señalar un alto valor de densidad de estos topónimos en el primer intervalo de distancia, comprobamos que se trata tan solo de un dato, y por ello no es excesivamente fiable. Por otro lado se da un fuerte crecimiento de la densidad a partir de los 1000 metros de distancia, lo cual indica que los yacimientos romanos no estaban excesivamente cerca de los lugares con nombre en "-obre". Sin embargo, podemos pensar que esta distancia indicaría la posible separación entre los antiguos asentamientos de carácter indígena, como parecen ser los lugares en "-obre" (que hemos visto que se asocian espacialmente con los poblados castreños) y los asentamientos romanos, cercanos a los anteriores pero en emplazamientos diferentes, más cercanos a vías de comunicación y a áreas de interés político y económico.

\section{ANALISIS DE DENSIDADES SEGÚN LA DISTANCIA A LA RED HIDROGRÁFICA} (Figura 13)

Dejando ya el análisis de distancias a entidades de poblamiento, aplicaremos este mismo método al estudio de la influencia de un recurso natural esencial en la organización del poblamiento como es la red hidrográfica, para tratar de comprobar el papel de los recursos fluviales en la estructuración y cambios del poblamiento tardoantiguo y medieval en este territorio. En este caso, hemos optado por un radio de análisis menor: II anillos o "buffers" de 200 metros cada uno, dada la intensa presencia hidrográfica en esta zona. Por otro lado, consideramos que más lejos de la distancia total de estudio (2200 metros) no se ejercería una influencia directa del curso de agua en la entidad a estudiar, especialmente en una zona como esta, tan rica en arroyos y pequeños ríos. Como comprobaremos, las tendencias generales son muy claras y similares.
En el caso de los poblados castreños, encontramos una alta y creciente densidad de los mismos a partir de los 200 metros de distancia al curso de agua (a menos distancia, lógicamente, la densidad es muy baja, ya que se trata de terrenos excesivamente bajos y húmedos para un asentamiento humano) hasta los 800 metros de distancia, donde la densidad de castros alcanza su máxima cota, para descender fuertemente a continuación (a pesar de lo que parecen indicar los picos observados a continuación, que no son significativos por basarse en escasos datos) hasta desaparecer a los 1600 metros de distancia.

Los indicadores de época y cultura romana muestran una gráfica de densidad muy semejante, que crece de forma más o menos continua (recordamos que lo importante en esta interpretación es la tendencia general) hasta 1200 metros de distancia al curso fluvial, para descender a continuación con bastante fuerza, de modo que en torno a los 1400 metros desaparece.

Una tendencia muy parecida de cercanía a la red hidrográfica se obtiene al analizar la densidad de las entidades de poblamiento alto y plenomedieval en Nendos, es decir: villae, entidades secundarias, entidades eclesiásticas. En estas gráficas se repite con gran similitud la misma curva: una densidad creciente de poblamiento entre los 0 y 800 metros de distancia del río. A partir de este intervalo medio decae fuertemente la densidad (aunque puedan aparecer algunos picos que realmente son poco significativos) hasta desaparecer en torno a los 1200 y 1600 metros de distancia.

En cambio, los topónimos referentes a castillos no parecen tener una relación excesivamente clara o fuerte con la red fluvial. Los valores de densidad obtenidos para las distancias más cercanas a los ríos se ajustan con bastante nitidez a los valores medios esperados en el caso de no existir una influencia directa entre ambos tipos de datos y solo entre los 1000 y 1200 metros de distancia aumenta significativamente la densidad de este tipo de topónimos. Quizá podemos explicar esta gráfica (realmente la única que no responde a la cercanía 
a los recursos fluviales) de nuevo por la función y características de los hipotéticos castillos que existirían en estas zonas, que buscan para su emplazamiento lugares diferentes a los de asentamientos de habitación, es decir, puestos más elevados y con un cierto dominio visual sobre el territorio, lugares todos ellos que no suelen coincidir de manera inmediata con los cursos de agua, que se encuentran generalmente en zonas más bajas o de valle. Esto hace pensar en otro tipo de estrategias de captación de agua en estas posibles fortificaciones, como aprovechamiento de manantiales subterráneos o recogida de agua de lluvia. Por otro lado, si observamos el mapa de distribución de estos topónimos, comprobaremos que una de las zonas de mayor concentración de los mismos sería la parte norte costera de Nendos (probablemente con funciones de vigilancia y control marítimo), donde sabemos que existen menos cursos de agua, pero en cambio se tiene acceso a otro tipo de recursos acuíferos, como son los marinos.

\section{Índices de dispersión}

El grado de dispersión de una distribución constituye un dato de valor fundamental en un análisis territorial. Estadísticamente, una distribución puede ser casual, ordenada o agregada. La distribución casual o aleatoria es aquella en la que teóricamente no existe ningún factor condicionante en la colocación de los puntos en el espacio, por lo que se distribuyen al azar. Una distribución ordenada o regular es aquella en la que los puntos se colocan uniformemente entre sí, con un criterio homogéneo y común de distribución. Una distribución agregada o concentrada es aquella en la que los puntos tienden a agruparse en determinadas zonas, dejando otras más vacías. Por tanto, el análisis del grado y las características de una dispersión puede ofrecernos una información muy útil para conocer la organización del espacio en un área determinada. Sin embargo este análisis no puede realizarse a simple vista (como lamentablemente se hace con frecuencia en historia y arqueología) puesto que muchas veces el grado de dispersión no es apreciable con claridad para el ojo y el cerebro humano y puede llevar a errores e interpretaciones sub- jetivas. Es por ello necesario recurrir a índices de dispersión que nos permiten conocer y confrontar de forma objetiva el grado y características de una distribución. El cálculo del índice de dispersión se basa siempre en el supuesto inicial de la aleatoriedad de una distribución, esto es, que a priori una distribución sin condicionamientos tiende a ser casual y por ello su índice de dispersión será igual a I, siendo la varianza sobre este valor esperado la que nos informa de las características de esa distribución.

Existen diversos métodos para estudiar los índices de dispersión, siendo los más conocidos el análisis de cuadrados y el cálculo del vecino más próximo. En nuestro caso, por limitaciones de espacio, recurriremos solamente al primero, si bien resulta útil contrastar los resultados con diversos métodos.

El análisis de cuadrados consiste en la subdivisión del área a estudiar a través de una red de cuadrados iguales y la observación del número de puntos que corresponden o "entran" en cada uno de los cuadrados o celdas (HODDER; ORTON, 1990: pp. 45-5I). Esto permite crear mapas de zonas de mayor y menor densidad de puntos así como histogramas de frecuencias observadas (es decir, el número de cuadrados que contienen $0,1,2 \ldots$ puntos). Según la propiedad de la función de Poisson, en una distribución aleatoria, sin ningún condicionante directo, la media del número de puntos esperados en cada cuadrícula y la varianza son iguales, por lo que la razón de su cociente sería I. En caso de una distribución ordenada o regular, esta razón sería menor de I, y para el caso de una distribución agregada, el índice sería mayor de 1 .

Este método ha sido usado con frecuencia en arqueología para el análisis de distribución de artefactos dado que generalmente los materiales en un yacimiento se recogen también en función de una retícula y ha permitido obtener datos de gran interés que visualmente no podrían apreciarse en un mapa de distribución de puntos. Sin embargo, el método de cuadrados presenta algunos problemas. En primer lugar, la elección del tamaño de las celdas, puesto que los resultados pueden variar seriamen- 
te según la dimensión del cuadrado que se utiliza. Esto se puede solucionar calculando el tamaño óptimo de la celda (HODDER; ORTON, 1990: pp. 47-48). Otro problema que presenta el método de cuadrados es el de establecer el origen de coordenadas de la retícula o parrilla de celdas ya que cambiándolo ligeramente de lugar, se producen resultados diferentes a pesar de ser la misma concentración de puntos. Una posible solución sería dejar caer repetidamente y de forma aleatoria una única celda en distintas partes de una distribución, creando así directamente un histograma de frecuencias. Otra solución, que será la que nosotros usaremos, es la de repetir el análisis con la misma retícula con diferentes orígenes de coordenadas, para calcular la media de todos los índices de dispersión obtenidos.

A continuación veremos algunas posibilidades de análisis e interpretación del espacio y poblamiento del territorio de Nendos en la Edad Media a través de este método de cuadrados. De nuevo hay que recordar que lo importante de este análisis para este trabajo no es el valor absoluto obtenido en sí, sino como indicador de una tendencia de distribución determinada, es decir, agrupada, ordenada o aleatoria. También en este test usaremos el programa SAU, dado que nos permite realizar este tipo de análisis de forma rápida, completa y eficaz, como veremos a continuación.

En el caso de los castros o poblados de época y cultura castreña conocidos en el territorio de Nendos, se puede considerar que poseemos una cantidad altamente representativa de localizaciones de dichos castros que no estaría lejos de la cantidad total de los mismos que llegó a existir en este territorio. Por ello, constituye un buen conjunto para analizar con este método (Figura 5). En este caso, el tamaño ideal u óptimo de la celda cuadrada está en torno a los 2780 metros de lado y la dimensión ideal de la retícula establecida es de ||$x \mid$ | celdas, ya que permite cubrir todos los puntos y prácticamente la totalidad del territorio con una parrilla cuadrada. Obtenemos de esta forma una varianza de 0,862 y una media de 1,0, resultando por tanto un índice de dispersión de 0 , 862. Este valor señala hacia una distribución ordenada o tendente a la uniformidad. Para intentar obtener una cifra media estimativa realizamos de nuevo este análisis en otras 9 ocasiones, cambiando cada vez la posición de la parrilla y obteniendo una serie de 10 índices de dispersión cuya media total sería 0,731. Todos estos valores, en mayor o menor medida corroboran el primer resultado, es decir, un índice de dispersión menor de I, y por tanto indicativo de una distribución ordenada.

A continuación aplicaremos este test al caso de las villae de Nendos localizadas en la documentación. En el caso de las 33 villae datadas en torno al año 1000 obtenemos un índice de dispersión medio de 1,798, lo cual refleja claramente una distribución agregada o concentrada en determinadas zonas. En cuanto a las villae documentadas y localizadas en este territorio a la mitad del siglo XIII, (en total, 84) encontramos un indicador similar, aunque menos acentuado, cuyo valor es de 1,286, lo que señala un crecimiento de la uniformidad de la red de villae conocidas.

En cuanto a las entidades eclesiásticas de las que tenemos noticia en Nendos, en torno al año 1000 obtenemos una distribución media de 1,4655, es decir, de carácter claramente agregado, mientras que alrededor del 1250 , el valor medio de la distribución sería de I,067।, lo cual indicaría una disposición aleatoria o no agregada de dichas entidades eclesiásticas.

En continuidad con este último análisis puede ser interesante realizar también este test a la distribución de las parroquias actuales del territorio de Nendos, ya que si bien no se trata propiamente de datos del periodo medieval, sabemos que su estructura refleja en muchos casos una organización mucho más antigua del paisaje. En este caso obtenemos 10 valores muy similares cuya media es 0,7236 . Esto refleja, como era de esperar, una distribución de la red parroquial que tiende hacia la ordenación regular o uniformidad a lo largo del territorio, para cubrirlo y organizarlo del modo más completo y eficaz posible.

En cuanto a los testimonios de época y cultura romana y galaicorromana, los datos con 
que contamos parecen reflejar una distribución tendente a la ordenación o uniformidad: 0,9338 (con una parrilla de $6 \times 6$ celdas de 5000 metros de lado). Aunque estos datos son más bien escasos e incompletos, podemos pensar que sí reflejan una tendencia general de los yacimientos romanos a distribuirse de forma más o menos regular a lo largo del territorio.

También a través de este análisis observamos que el conjunto de los topónimos referentes a "castillos" presenta una distribución de carácter agregado o concentrado, puesto que con una red optimizada de $8 \times 8$ celdas de 4000 metros de lado cada una, obtenemos un valor medio de 1,3696. Este resultado se diferencia de los valores obtenidos para la red de castros, señalando de nuevo su diferente emplazamiento y distribución y contradiciendo la tradicional idea de la concentración de estos topónimos relativos a castillos en torno a lugares donde existieron castros.

\section{Polígonos de Thiessen}

El polígono de Thiessen representa el área teórica más inmediata a un punto con respecto a sus vecinos. Dicho de otro modo, sería todo el espacio al que desde un punto se accede más rápido que desde cualquier otro. Gráficamente esta superficie se halla trazando perpendiculares por el medio de las rectas que unen los diferentes puntos del conjunto (HODDER; ORTON, 1990: p. 72).

Para el estudio histórico de los territorios el cálculo de estos polígonos puede resultar de gran utilidad, puesto que nos permiten conocer cual sería, siempre teóricamente, el área de dominio de un núcleo, asentamiento o cualquier otra entidad espacial, así como realizar estudios comparativos. Sin embargo, hay que señalar que los polígonos de Thiessen son una construcción artificial y estadística que no tiene en cuenta factores condicionantes de la realidad como el relieve, la hidrografía... que en muchas ocasiones influyen en la delimitación de un territorio ${ }^{10}$ y sobre todo, no tienen en cuenta el factor humano, que no siempre adecua las fronteras a la forma más lógica o eficaz, sino a intereses de muy diverso tipo. No obstante, como estamos repitiendo a lo largo de este trabajo, estos cálculos estadísticos y espaciales sí son útiles e importantes en la medida en que nos muestran tendencias, que serán más claras y fiables cuanto mayor sea el número de datos empleados. En este sentido los polígonos de Thiessen suponen una aproximación, una posible reconstrucción de los límites territoriales históricos que puede ayudarnos a conocer y comparar mejor la organización, estructura y evolución del espacio humanizado a lo largo del tiempo. En nuestro caso, intentaremos reconstruir la posible red territorial de castros y villae, contrastándolas entre sí y también con el actual mapa de parroquias.

La mayoría de los programas GIS permiten la creación de estos polígonos a través de sencillos procesos. No obstante consideramos que puede ser más útil calcular primero estos polígonos a través de SAU, que nos facilita además una serie de datos numéricos y estadísticos sobre dichos polígonos como la media del área, del perímetro y del número de lados de las superficies resultantes, y exportarlos luego al programa GIS para su estudio y comparación, como veremos a continuación.

Teniendo siempre en cuenta la limitación de los datos que poseemos, no podemos pretender realizar una reconstrucción y comparación territorial de las distintas redes de poblamiento a lo largo de la historia de Nendos, pero sí intentar atisbar sus relaciones más generales. En el caso de la red de castros del territorio de Nendos, en las zonas donde poseemos una mayor fiabilidad de los datos recogidos, el número medio de lados de los polígonos obtenidos sería de 5,8 lados, el área media del territorio de cada castro sería de 5,587 $\mathrm{km}^{2}$ y el perímetro medio de 9,25 km. Al aplicar este análisis a las

\footnotetext{
I0 La introducción de superficies de coste en futuros trabajos, como señalábamos anteriormente, permitirá paliar en cierta medida esta distorsión.
} 
villae documentadas en este territorio hasta el siglo XIII se obtiene de nuevo una media de 5 , 8 lados por polígono, un área media de 3,927 $\mathrm{Km}^{2}$ y un perímetro medio de 7,8 kilómetros. Al contrastar y superponer ambos mapas (Figura 6) comprobamos que en general no parece existir una relación espacial directa entre el territorio teórico de los castros y la red de villae medievales, aunque sí diversas correspondencias en algunos casos particulares. Sabemos que estamos trabajando con meros modelos teóricos, por lo cual no podemos postular ninguna relación inequívoca, pero de forma aproximada podemos constatar que en general el territorio del castro sería algo mayor que el de la villa medieval (en este caso corresponde aproximadamente a 1,4 veces el territorio de la villa). También podemos apreciar visualmente que en ciertos casos, los límites del territorio de un castro corren cercanos y paralelos al de un conjunto de dos o más villae, pudiendo indicar la división de la antigua territorialidad castreña en la delimitación de dos o más villae medievales, como también señala $\quad$ M. Fernández Mier para el caso asturiano (FERNÁNDEZ MIER, 1999).

Al introducir en el análisis el actual mapa de límites de parroquias obtenemos algunos resultados más interesantes. El área media del territorio parroquial en Nendos es de 4,2 $\mathrm{Km}^{2}$ y el perímetro medio de $8,01 \mathrm{Km}^{2}$ (eliminando de nuevo del cálculo las parroquias periféricas de este territorio, que por otro lado, son las más grandes, para poder comparar más correctamente con los datos sobre villae y castros). Al contrastar los límites de las parroquias con los límites establecidos por los polígonos de Thiessen para los castros, no encontramos una relación precisa, aunque sí se puede constatar la cercanía y similitud entre algunos límites de castros y de parroquias actuales. El territorio medio de un castro en esta zona sería aproximadamente I,3 veces el de una parroquia y su perímetro poco menos del doble. En cambio sí hallamos una coincidencia bastante significativa al confrontar los límites de las parroquias actuales con los de las villae conocidas hasta el siglo XIII. A nivel numérico observamos que el área y perímetro medio de la parroquia $\left(4,2 \mathrm{Km}^{2}\right.$ y $8 \mathrm{Km}$ respectivamente) son muy similares a los correspondientes a la villa $\left(3,927 \mathrm{Km}^{2}\right.$ y 7,8
$\mathrm{Km}$ ). Gráficamente comprobamos que en frecuentes ocasiones coinciden con bastante claridad ambos territorios. Esta coincidencia aumenta si en vez de usar el mapa de parroquias reales empleamos en la comparación la reconstrucción de polígonos de Thiessen para las parroquias (Figura 7). De esta forma vemos que en al menos 15 de los 83 casos analizados (es decir, en un 18\%) existe una clara correspondencia o similitud, alcanzando en casos como Mabegondo (Abegondo), Pravío (Cambre) o Crendes (Abegondo) una coincidencia prácticamente total. Por otra parte, podemos pensar que esta coincidencia podría ser mayor si dispusiésemos de las localizaciones precisas de aquellas villae que solo hemos podido localizar con una fiabilidad media.

\section{Análisis de interpolación o proximidad}

Una superficie de interpolación es una forma de representar gráficamente tendencias de distribución de puntos, permitiendo definir valores no visibles a partir de valores visibles. Aplicado a la cartografía esto no es otra cosa que un mapa de densidad, es decir, la representación de las zonas en las cuales hay mayor número de puntos por unidad de superficie (MACCHI JÁNICA, 200I: pp. 73-78). Para elaborar estas superficies de interpolación se debe realizar un análisis de proximidad, esto es, el cálculo para cada punto del número de vecinos que posee en un radio determinado. La elección de ese radio de estudio es fundamental en este tipo de análisis ya que puede condicionar considerablemente el resultado.

Un primer ejemplo puede ser la suma y superposición de la interpolación de castros de Nendos con la de los topónimos acabados en "-obre" de esta zona. Tras realizar el cálculo de la interpolación con SAU observamos que los castros tienden a concentrarse más en la zona costera y en el centro del territorio de Nendos mientras que los topónimos en "-obre" en cambio parecen presentar una mayor densidad en toda la franja central que recorre Nendos de izquierda a derecha y no, en cambio, en los límites inferiores y superiores. Ya en el programa GIS, mediante una reclasificación de los valores del mapa raster, asignamos el valor 
0 a las zonas de densidad menor de la mediana tanto de topónimos en "-obre" como de castros, el valor I a las zonas con densidad de castros mayores de la mediana y el valor 2 a las zonas con densidad de topónimos en "obre" mayores de la mediana. De esta forma, al sumar ambos mapas raster obtenemos un nuevo mapa en el que además de dichos valores 0,1 y 2 aparece el valor 3 que representa las zonas en que coinciden una mayor densidad de castros y una mayor densidad de topónimos acabados en "-obre". Esta coincidencia se localiza principalmente en la zona central de Nendos, lo que nos indica que en ella se da una cierta tendencia a la pervivencia y continuidad de asentamientos de origen prerromano en época romana.

Con el mismo procedimiento se pueden crear otros muchos mapas comparativos. Detallaremos a continuación solo aquellos que consideramos de mayor interés para el conocimiento de la estructura espacial, poblamiento y evolución del territorio medieval de Nendos. La coincidencia (usando como en el caso anterior un radio de análisis de 3000 metros) entre las zonas de más densidad de castros y las de más densidad de indicadores de época romana, es un área muy pequeña y restringida, que correspondería aproximadamente a las parroquias de Cañás, Sergude, Sarandóns y Figueroa, todas en los límites entre Carral y Abegondo. Por otro lado, como acabamos de ver, esta zona también se encuentra dentro del área de mayor densidad de topónimos en "-obre". No es extraño que sea en esta zona de Nendos donde se da esa mayor convergencia entre cultura castreña y romana, puesto que se trata de una zona de gran riqueza minera que ha sido explotada desde la antigüedad, tanto por el mundo castreño como por el romano. Puede ser también interesante confrontar las zonas con una mayor densidad de topónimos sobre castillos con aquellas de mayor densidad de poblados castreños. Parece interesante señalar en primer lugar que existe una mayor concentración de topónimos relativos a castillos en las zonas limítrofes de este territorio, es decir, en la costa norte y en el extremo central sur. El resultado de la superposición muestra que sí existe una cierta coincidencia entre ambos fenómenos, aunque no tanta como para asociarlos (tal y como se pensaba al inicio), y que dicha convergencia se localiza tanto en la zona costera occidental del norte de Nendos como en el extremo sur central del territorio.

En cuanto a la relación entre zonas con mayor densidad de castros y zonas con mayor densidad de villae, observamos (Figura 8) que alrededor del siglo XIII la coincidencia entre ambas se localiza, de nuevo, en la zona central del territorio y en la costa nororiental; es decir, en prácticamente todo el municipio de Sada, en parte de Oleiros y Bergondo, en el centro del municipio de Carral, de Cambre y en el límite entre Oza dos Ríos y Cesuras. Todas ellas son áreas que parecen concentrar una mayor densidad de poblamiento desde época antigua hasta la actualidad (BOUHIER, 200 I: pp. 99-138), debido principalmente a sus condiciones geográficas: por un lado la cercanía al mar y por tanto, el aprovechamiento de sus recursos, y por otro lado la ubicación en el amplio (y prácticamente único en todo Nendos) valle que forma el río Mero en la zona central de este territorio, condicionando claramente la disposición de las villae a lo largo de su curso.

A través de este mismo proceso se pueden superponer más de dos mapas, sumando primero dos, y a continuación sumando al resultado obtenido el tercer mapa. Esto puede ser interesante para conocer y analizar áreas de mayor poblamiento a lo largo de la historia. Por ejemplo, podemos sumar y superponer en un solo mapa las áreas de mayor densidad de castros, villae y parroquias (Figura 9). El resultado no difiere excesivamente del obtenido al sumar la interpolación de la red de castros y villae, ya que como estamos viendo, en general las parroquias representan una clara continuidad con el territorio de las villae. Así, las zonas de mayor poblamiento conocido de castros, villae medievales y parroquias actuales estarían de nuevo en prácticamente todo el municipio de Sada, en parte de Oleiros y Bergondo, en el centro del municipio de Carral, de Cambre y en el límite entre Oza dos Ríos y Cesuras, y corresponderían a las zonas con mayor poblamiento y continuidad habitativa a lo largo de los últimos veinte siglos en este territorio. 


\section{INTERPRETACIÓN. \\ EL TERRITORIO DE NENDOS ENTRE LA ANTIGÜEDAD Y LA PLENA EDAD MEDIA}

De nada sirven al historiador los datos de la informática, la estadística ni cualquier otra metodología si no se plasman en una interpretación relacionada y contextualizada de los resultados. Precisamente en este epígrafe intentaremos sintetizar y explicar históricamente los datos que hemos obtenido a lo largo del proceso de construcción de un SIG y de análisis espacial sobre el territorio de Nendos entre la Tardoantigüedad y la Plena Edad Media, como caso representativo de evolución del territorio y la articulación espacial en la Galicia medieval. En este sentido, nos centraremos principalmente en la organización interna del territorio entendido, como ya hemos dicho, como la suma del medio físico y los hombres, y siempre desde una perspectiva amplia y cuantitativa que tratará de buscar más las tendencias y procesos generales que los casos particulares, aunque siempre reconociendo en ellos su propia base.

Según los datos recavados en esta investigación, podemos establecer cuatro etapas que en absoluto representan rupturas sino más bien fases de una evolución lineal:

\section{Poblamiento antiguo en el territorio de Nendos (SS. I-V D.C.)}

Los datos arqueológicos sobre el poblamiento castreño en la zona (NAVEIRO LÓPEZ, 1994: pp. 20-40) de nuestro estudio no son muy abundantes. Concretamente en el territorio de Nendos solo han sido excavados los castros de Castromaior (Abegondo) y Meirás (Sada), aunque también hay datos de excavaciones de castros cercanos, siempre dentro del llamado Golfo Ártabro, como son el de Nostián, (Arteixo), Lobadíz (Ferrol), Elviña (La Coruña) y Pastoriza (Arteixo). En general, todos ellos muestran un momento de auge en torno al cambio de Era e inicio de la administración romana, abandonándose posteriormente, entre finales del siglo I y primera mitad del siglo II d. C.
Sin embargo, los datos que hemos analizado a lo largo de estas páginas nos permiten profundizar algo más en el conocimiento del poblamiento castreño de Nendos y su distribución espacial. En cuanto a su emplazamiento, en general comprobamos que los castros de esta zona -exceptuando los costeros- se sitúan entre los 80 y 200 metros de altura aproximadamente sobre el nivel del mar, en cimas de montes 0 a media ladera. Otro factor condicionante en el emplazamiento de los castros es su cercanía a los cursos de agua. En este sentido, el análisis de densidad según la distancia corrobora la relación entre los castros y la red hidrográfica, pues generalmente el castro se halla entre los 200 y 700 metros de distancia a un curso fluvial.

En cuanto a la estructura espacial de este tipo de poblamiento, tal y como hemos observado a través del cálculo de los polígonos de Thiessen, se puede apuntar que el área media y teórica de dominio territorial de cada castro sería de unos $55 \mathrm{~km}^{2}$, en un circuito alrededor del castro de $9 \mathrm{~km}$ de perímetro. De esta forma, aunque existen diferencias entre el tamaño e importancia de los castros, el conjunto de los mismos parece formar una red que cubría el territorio de forma relativamente uniforme y ordenada, como se puede comprobar a simple vista en el mapa de distribución de castros, o de forma más precisa a través de sus índices de dispersión. Obviamente no podemos hablar de distancias fijas entre castros, pero sí se puede apuntar una media de 1700 metros de distancia entre ellos, un valor similar al que considera Carballo Arceo para la generalidad de la distribución de castros en Galicia (CARBALLO ARCEO, 1996). Por otro lado, aunque la distribución de este tipo de poblamiento tienda a la uniformidad, existen diferentes densidades de castros según la zona. Así existe una mayor concentración de poblamientos castreños en primer lugar, en el área costera de Sada, que parece deberse al aprovechamiento de recursos marinos así como a la capacidad de defensa y control que supone este emplazamiento. Otra zona de mayor densidad de castros es la parte central de Nendos, en relación probablemente con la explotación agrícola del fértil valle del Mero y quizá 
también con la riqueza minera de la zona correspondiente a los límites municipales de Carral y Abegondo.

Sobre el proceso de abandono de los castros, el estudio de la distribución de los topónimos en "-obre" podría aportar algunos indicios de interés. Mediante el análisis de densidades según la distancia, hemos podido constatar que existe una clarísima relación espacial entre los lugares de topónimo acabado en "-obre" (o sufijos afines), específicos de la zona Noroeste de la provincia coruñesa y cuyo origen, según los filólogos, sería prerromano, y la existencia de un poblamiento castreño en las inmediaciones. Dado que todos estos lugares con topónimos en "obre" siguen poblados en la actualidad, podemos hablar de una gran continuidad habitativa en el espacio humanizado de estos lugares a lo largo de la historia. Sin embargo, aunque hemos comprobado que en general el castro está a menos de 500 metros del núcleo con topónimo en "-obre", los emplazamientos de ambas entidades son bastante diferentes, por lo que se debe desechar la inicial idea de una total continuidad espacial y temporal entre el castro y el actual núcleo con nombre en "-obre". Los topónimos en "-obre" se hallan en terrenos más bajos y llanos que los castros, como se comprueba visualizando las curvas de nivel. Además, como comentaremos más adelante, existe una mayor relación y cercanía espacial de estos topónimos hacia los yacimientos romanos. Todos estos datos parecen ofrecer una secuencia cronológica interesante, ya que que en general el hábitat en valle es posterior históricamente al poblamiento castreño, pero a la vez sabemos que el origen de estos topónimos corresponde a un sustrato indígena anterior a un grado avanzado de romanización o "latinización". Por tanto, podríamos conjeturar que ambas entidades, castro y topónimo en "-obre", reflejan el cambio del hábitat castreño en altura al núcleo en el valle, y que este se produciría en un momento no muy avanzado tras la conquista romana, dado que en el nombre del nuevo núcleo en el valle pervive fuertemente el componente indígena prerromano. Por otro lado, este sustrato indígena podría hacer pensar que en este proceso existió más bien una iniciativa activa de toda o parte de la población indígena ártabra, y no tanto una imposición forzada. Como vemos, se trata tan solo de una hipótesis, pero que parece concordar tanto con la organización espacial denotada, como con las interpretaciones generales sobre los cambios en el hábitat galaico tras la conquista romana. En este sentido, hay que recordar que es posible, según los paralelos con otras zonas de Gallaecia, la continuidad del poblamiento en algunos castros hasta épocas más tardías, pero en general, según los indicios expuestos y el relativamente alto grado de romanización del territorio, como veremos a continuación, podemos considerar que el proceso de cambio del tipo de hábitat dominante en Nendos fue más bien rápido y temprano.

En cuanto a los yacimientos y restos atribuibles a época romana que conocemos en esta zona, parece posible establecer una cronología amplia para todos ellos, entre el siglo I y $\vee$ d. C., y clasificarlos en diversos tipos: asentamientos habitativos o productivos (agrícolas, factorías de salazón, horno cerámico...), restos de actividades mineras, enterramientos 0 aras votivas. Aunque su número no es muy alto (20 para todo el territorio), debido a la escasez de estudios arqueológicos, denotan una explotación del territorio relativamente amplia y una distribución que parece ordenarse de forma regular por Nendos, tal y como informan los índices de dispersión, y como se puede observar visualmente (cierta tendencia al alineamiento horizontal y vertical de estos yacimientos). Esta disposición podría hacer pensar en una distribución a lo largo de vías de comunicación, como es frecuente en los asentamientos romanos. Por otro lado, estos yacimientos se hallan en o muy cerca de actuales núcleos de población, lo que indica una gran continuidad espacial y temporal del poblamiento y hace pensar que muchos otros restos de época romana probablemente se encontrarán bajo actuales centros de población.

Por tanto, la presencia e influencia romana en el territorio de Nendos parece haber sido relativamente intensa, al menos en relación con otras zonas de Gallaecia, debido al interés de Roma en esta zona, importante especialmen- 
te desde el punto de vista de las comunicaciones marítimas y de sus posibilidades mineras. Por ello también podemos pensar en un proceso de romanización no excesivamente lento ni problemático en este territorio, que impulsaría un cambio de hábitat del castro al llano relativamente temprano, como se ha comentado anteriormente.

El emplazamiento concreto de estos yacimientos romanos o galaicorromanos de nuevo parece estar influido por la distancia al mar y a la red fluvial, pero en menor medida que en el caso de los castros. Esto podría explicarse en base a las diferentes funciones asumidas por los asentamientos romanos en comparación con los castros. Mientras que en estos últimos el emplazamiento respondía principalmente a una finalidad básicamente agraria y de control zonal, razón por la que la cercanía a los cursos de agua era fundamental, en el caso de los asentamientos romanos, sin dejar de ser esencial el acceso a los recursos hidrográficos, entran en juego otros condicionantes como la proximidad y relación con la red viaria o las explotaciones mineras. En cuanto a la posición geográfica concreta de estos yacimientos romanos, en general se asientan en zonas bajas y llanas, a diferencia de los castros, si bien en algún caso como en la Espenuca (Coirós), sí se aprovechan posiciones elevadas.

Aunque las zonas de más densidad de yacimientos de época romana apenas coinciden con las zonas de mayor densidad de castros, en los análisis de cercanía comprobamos que existe una nítida relación espacial entre los yacimientos romanos y los poblados castreños, que generalmente se hallan a menos de 1000 metros de distancia. Sin embargo, en el caso de los topónimos en "-obre", está relación es aun más clara, estando mayoritariamente a menos de 500 metros de los yacimientos romanos (y en casos como el de Tiobre, en Betanzos, el yacimiento romano se halla en el propio núcleo de topónimo en "-obre"). Esto parece confirmar la hipótesis anteriormente expuesta sobre el origen de estos núcleos en "-obre" en relación con la conquista y presencia romana en este territorio, siendo quizá las primeras comunidades en realizar el cambio de hábitat.
Concluyendo, a lo largo de este periodo se desarrolla un proceso en el que se abandona el castro como forma principal de hábitat por un asentamiento en llano de tipo villa o vicus. Los motivos de ese cambio son múltiples, pero destacaremos tres. Por un lado, con los cambios que comporta la conquista y la estabilidad de la administración romana desaparecen las razones para emplazamiento en altura de los asentamientos indígenas. Por otra parte, el asentamiento en el llano supone una mayor cercanía y un mejor control de las tierras explotadas en el valle. Por último, no deja de ser importante el fenómeno de emulación de los modelos de asentamiento y explotación romanos. Estos asentamientos romanos estarían ocupados en un principio por los conquistadores, pero a medida que avanza el proceso de aculturación, elementos de la sociedad indígena se integrarán en los nuevos modelos de ocupación y explotación del territorio. En este sentido, la villa, los vici, y otros tipos de asentamientos rurales en el valle, se van extendiendo entre los siglos I y $\vee$ d. C. por todo el territorio, a medida que se abandonan los anteriores modelos habitativos castreños.

\section{El territorio de Nendos entre la Tardoantigüedad y la Alta Edad Media (SS. V-VIII)}

En esta etapa no disponemos prácticamente de datos documentales o materiales -a excepción de algunos problemáticos restos de necrópolis- que nos permitan acercarnos al conocimiento de la estructura territorial de esta zona. Por esta razón en esta fase de nuestro trabajo recurriremos al establecimiento de "puentes" entre los datos de épocas previas y posteriores a esta etapa, para tratar de reconstruir así algunas de las características del territorio y la red de poblamiento de Nendos entre los siglos $\mathrm{V}$ y VIII.

Los escasos restos materiales encuadrables en la Tardoantigüedad y Alta Edad Media conocidos en Nendos pertenecen todos ellos a enterramientos y necrópolis de las que no existen demasiados datos. Por todo ello, no se han podido realizar para esta época todos los aná- 
lisis espaciales propuestos a lo largo del trabajo. Sin embargo, la propia disposición espacial de estos restos puede ya ofrecernos datos de gran interés. Las seis necrópolis conocidas se concentran, curiosamente, en una zona reducida, cerca de los límites entre Coirós, Paderne y Betanzos (Figura 2). En todos los casos, estos restos se localizan en lugares que actualmente continúan poblados, y en cinco de los seis casos totales coinciden con una iglesia parroquial actual, cuyo cementerio adosado supone la continuidad de esas necrópolis altomedievales y a veces tardorromanas. En relación con esto, también el análisis de cambios en las densidades nos informa de la nítida asociación espacial entre centro religioso medieval y necrópolis altomedieval. Efectivamente, en el mapa de ambas entidades se comprueba que en la mitad de las necrópolis en Nendos existe una iglesia anterior al año 1250, que actualmente pervive como parroquia. Esto nos informa en primer lugar de una clara continuidad ocupacional de dichos lugares a lo largo del tiempo. Por ello, podemos pensar que la presencia de enterramientos o necrópolis altomedievales en un lugar se puede interpretar como la existencia también de un lugar de culto y un poblamiento en dicho momento en ese lugar, o muy cerca de él. Si bien en arqueología medieval la asociación necrópolis-hábitat no es siempre clara (AZKARATE GARAI-OLAUN, 1992; LA ROCCA HUDSON; HUDSON, 1987; QUIRÓS CASTILLO, 2003), en el caso del poblamiento rural tradicional gallego, parece constatarse claramente este binomio.

En este sentido, las seis necrópolis se sitúan en la proximidad de los ríos (a menos de 600 metros de un curso de agua, como indica el análisis de cambios en las densidades) y en zonas más bien llanas (excepto en el caso del monte de A Espenuca), de forma similar al emplazamiento de los yacimientos romanos. Pero esta relación de las necrópolis (y sus consiguientes probables asentamientos) altomedievales con los yacimientos de época romana parece ser aun más profunda, como demuestra el análisis de densidad según la distancia, en el que se observa una gran cercanía entre ambas entidades. Esta relación, que en cambio no parece darse de forma significativa con el poblamiento castreño, se confirma al constatar que en tres de los lugares donde se han hallado estas necrópolis: Tiobre, Santiago de Ois y Santa Eulalia de la Espenuca, existen restos de asentamientos de época romana, y en los demás casos, el yacimiento romano más cercano conocido está a menos de 3000 metros.

Todo esto nos hace pensar, a pesar de la problemática y escasez de los datos, que en general no se produciría una ruptura entre los lugares de habitación y explotación en época romana y los asentamientos en época tardorromana y altomedieval, sino que existe una tendencia a la continuidad habitativa a lo largo del tiempo.

De forma similar, los datos que poseemos para épocas posteriores nos permiten confirmar esta hipótesis. Como ya hemos dicho, la información documental sobre entidades del poblamiento medieval de Nendos comienza a partir del siglo IX. No obstante, como bien sabemos, la fecha de mención de una entidad no equivale a la aparición de dicha entidad de poblamiento, sino que puede proceder de mucho tiempo atrás. Así, en cuanto a los indicadores de época romana, en 9 casos como mínimo tenemos datos de una entidad de poblamiento entre los siglos IX y XIII en el mismo lugar donde se localizaba un asentamiento romano. Por tanto, conociendo que un lugar estaba habitado en época romana (según restos datables muy genéricamente entre el siglo I y $\vee$ d. C) y que ese mismo lugar continuaba poblado a partir del siglo IX, llegando en muchos casos ese poblamiento hasta hoy día, parece coherente pensar que en el periodo en que no poseemos datos del mismo, entre los siglos $\checkmark$ y VIII, debido a la carencia de documentos escritos por poderes señoriales y a la debilidad y falta de estudio de sus restos arqueológicos, este lugar continuase habitado sin cortes ni cambios bruscos en su evolución.

En este sentido, el análisis de cambios en las densidades según las distancias puede completar esta visión, ya que en general, las entidades eclesiásticas medievales se hallan muy cerca de un yacimiento romano, más de lo que lo están el resto de entidades de poblamiento 
medieval (núcleos de villa, villares, casales...). Revisando los datos de entidades religiosas (monasterios y/o iglesias) anteriores al año 1000 conocidas en Nendos, observamos que 4 de ellas están prácticamente en el mismo emplazamiento del yacimiento romano. Curiosamente, estos cuatro yacimientos romanos corresponden a aras votivas y restos de culto religioso romano. Si aumentamos la muestra a todas las entidades eclesiásticas conocidas antes del año 1250, la correspondencia aumenta a 5 centros de culto sobre yacimientos romanos, y si usamos los datos de las parroquias actuales de Nendos, la cifra de coincidencia es de 8 centros religiosos sobre restos romanos, en su mayoría restos cultuales y funerarios. Este fenómeno de asociación del centro de culto a un emplazamiento romano no parece ser infrecuente en arqueología medieval (ESCALONA MONGE, 1992, 1994) y nos puede aportar algunas ideas de interés. En primer lugar, corroboramos la idea anteriormente expuesta sobre la continuidad de las estructuras de poblamiento en este periodo "puente" entre dos épocas con información. Por otro lado, nos puede informar acerca de las estrategias de organización eclesiástica sobre el territorio, ya que en general, vemos que la iglesia en el momento de su implantación en Gallaecia, entre los siglos $\mathrm{IV}$ y $\mathrm{VI}$, aprovechó y adaptó en cierto modo las estructuras organizativas romanas ". De esta forma, las iglesias y/o cenobios, se fundan sobre estructuras romanas, generalmente centros de culto (que en casos como La Espenuca, en Coirós, provenían de un culto indígena anterior). Como ya se ha indicado, estos asentamientos romanos son en su mayoría de nueva planta, es decir, construidos sobre emplazamientos diferentes a los asentamientos indígenas, y desde su posición en el valle, actuaron como polos de organización y atracción del poblamiento. En este sentido, la iglesia, primero con la proclamación del cristianismo como religión oficial del imperio a finales del siglo IV, y después con la desarticulación del estado romano, se erige en parcial sucesora a nivel administrativo del poder imperial y continuará organizando en torno a sí el poblamiento. Este proceso de atracción y articulación del poblamiento es muy característico del poblamiento rural gallego y tiene su origen en el momento que estamos estudiando, entre los siglos $\vee$ y VIII.

Hasta ahora hemos hablado de lugares sobre los que poseemos datos de época antigua y medieval, pero, ¿qué hacer con los lugares para los que solo tenemos una parte del puente?, es decir, aquellos que solo sabemos que a partir del siglo IX estaban poblados, pero no poseemos datos de época romana en ellos. Según los análisis de cambios en las densidades que ya hemos comentado, generalmente cerca de las entidades de poblamiento conocidas antes del año 1000 se encuentra algún yacimiento romano localizado, y mucho más próximo, un castro. Esto reflejaría que en esa zona, aunque no sea ese lugar concreto, hubo un poblamiento antiguo, lo cual nos permitiría volver a construir el puente, aunque sea más largo e inestable. Pero también únicamente desde el siglo IX parece factible trazar una línea hacia atrás en el tiempo. Como ya hemos señalado, la documentación de esta época hace referencia con frecuencia a una serie de hechos que se remontan atrás en el tiempo y dejan entrever una organización territorial que no pudo iniciarse repentinamente en el siglo IX, sino que proviene de épocas anteriores: límites bien conocidos y delimitados, derechos sobre posesiones que vienen de "tiempos antiguos"... (PORTELA SILVA, 2002). Otro indicio, aunque siempre relativo y parcial, puede provenir del estudio de los topónimos que tenemos documentados a partir del siglo IX. Aunque no pretendemos en absoluto entrar en un tema que se escapa de nuestra formación, parece posible distinguir que aproximadamente la mitad de los 70 topónimos anteriores al año 1000 tendrían un origen indígena prerromano, como Porcimilio, Lemenione, Espelun-

I I A nivel conceptual, la iglesia sigue manteniendo hoy muchas herencias romanas: la lengua latina oficial, el panteón de santos, la idea de basilica, etc. que reflejan esta adaptación y continuidad de la estructura estatal romana en sus orígenes. 
ca, Karedugma, Collantres... además de los ya conocidos topónimos acabados en "-obre" y afines: Illobre, Caliobre, Cecebre... que podrían tener su origen al menos en época antigua, entre los siglos I y $\vee \mathrm{d}$. C, probablemente en una etapa no muy avanzada de la romanización. Debemos señalar con énfasis que en ningún caso se trata de certezas, ya que el topónimo de un lugar no equivale a su origen, pues pudo sufrir cambios de nombre a lo largo de su historia. Sin embargo constituye un indicio en un periodo de gran escasez de datos sobre la articulación del territorio.

En algunos castros de Galicia está documentada una continuidad o reocupación del poblamiento castreño en esta época debido a dicha inestabilidad política. En Nendos, debido a la falta de estudios arqueológicos, no poseemos datos que demuestren esta posibilidad. Sin embargo, según los indicios anteriormente señalados, no parece que la articulación territorial cambiase excesivamente durante este periodo con respecto a la evolución iniciada en época romana. Sabemos que el castro continúa siendo un referente espacial en el territorio, como se comprueba en la documentación a partir del siglo IX. No obstante, si hubo alguna reutilización del castro tras su abandono, esta debió ser más bien efímera y ocasional, ya que no se llega a desestructurar en ningún caso la organización del poblamiento proveniente de la etapa anterior.

Dicho poblamiento durante este periodo se organizaría en pequeñas comunidades rurales, al igual que conocemos para la etapa siguiente con las villae. En este sentido, consideramos que el problema del paso de la villa romana en sentido clásico a la villa medieval corresponde más a un problema terminológico que real. Ya hemos comentado como el patrón de villa romana en Gallaecia presenta una serie de divergencias con el modelo clásico (PÉREZ LOSADA, 1995), en su distribución, nivel de riqueza... El momento de mayor expansión de este tipo de asentamiento, en los siglos IV y V , corresponde también con una mayor ruralización de su carácter. Se puede pensar que la desaparición o absentismo de los propietarios galaicorromanos de las villae (RIPOLL; ARCE, 200I), debida a los cambios en los poderes políticos (ocupación sueva y visigoda) favorecería esa degradación y compartimentación de las estructuras de la villa, así como la progresiva independencia de los campesinos que en ella habitaban y trabajaban. Durante los siglos siguientes las villae seguirín ese proceso de ruralización hasta convertirse en explotaciones campesinas independientes, asimilables a aldeas que, no obstante, seguirán llamándose villae. Se produciría a la vez una generalización de este término, que englobará todo tipo de comunidad y explotación agraria, como eran los "vici" y otros núcleos de población rural. Se puede pensar, por tanto, en una progresiva evolución de una realidad a otra, bajo un mismo concepto.

Por tanto, al unir todos los datos y razonamientos expuestos, podemos considerar que entre los siglos IV y VIII, el territorio de Nendos continua la evolución iniciada en época romana sin grandes cambio ni bruscos cortes (SÁNCHEZ ALBORNOZ, 198I). Si bien no tenemos datos directos del poblamiento en esta época, hemos visto que existen claros lazos entre la ocupación del territorio a finales de la época romana y la que muestran los documentos a partir del siglo IX. En este proceso, la iglesia parece heredar en cierto modo el papel organizador y administrativo del estado romano, para concentrar y articular la población en el valle; población que se organizaría en las mismas pequeñas comunidades rurales que saldrán a la luz en la documentación de la siguiente etapa.

\section{El territorio de Nendos entre los S. IX y XI}

A partir de este periodo comienza a iluminar una cierta luz entre la oscuridad de datos de la época anterior gracias a la presencia de documentación escrita, y es precisamente en este momento cuando tenemos noticias por primera vez -concretamente en un documento de Sobrado del año 842- de la existencia de un territorio llamado Nendos. No obstante, como ya hemos explicado, es probable que esta delimitación espacial procediese de mucho tiempo atrás. En el periodo que nos ocupa, pare- 
ce que estos límites aproximados estarían entre los ríos Mandeo y Mero al este y oeste, en la costa norte y en torno a los límites actuales del municipio de Cesuras hacia el sur.

Como comprobamos en el contenido de la documentación, a partir del siglo IX una serie de poderes señoriales, en este caso monasterios e iglesias catedralicias, comienzan a apropiarse progresivamente de tierras y hombres en Nendos, mediante donaciones, compras y cambios, probablemente a través de métodos coercitivos (BARCELÓ, 1998: pp. 196-274), y buscan mediante la formalización por escrito de dichas adquisiciones asegurar sus dominios.

El mapa de entidades de poblamiento medieval conocidas entre los siglos IX y $X \mid$, muestra un territorio articulado principalmente sobre la villa, que sería la célula básica de la organización territorial, (de hecho, es con diferencia el tipo de entidad más citada en la documentación, con 1 II referencias a villae distintas). En concreto tenemos datos de 44 villae anteriores al año 1000. Visualmente se observa una tendencia de las villae a distribuirse a lo largo del eje oblicuo central del territorio de Nendos, dejando áreas de menos densidad en los extremos norte, este y oeste del territorio, que como ya hemos dicho, poseería en esta época unos límites más pequeños que en el periodo posterior.

En cuanto a las características de su distribución, según el resultado de los índices de dispersión, las villae que conocemos para esta época presentan una clara tendencia a la distribución agregada, mayor que la obtenida para épocas posteriores, lo cual refleja un poblamiento concentrado en áreas de más densidad, que parecen corresponder a zonas más fértiles y cercanas a los cursos de agua. Por otro lado, la visualización de las curvas de nivel, nos informa de que el emplazamiento de las villae coincide con zonas llanas o de valle. Además, según el análisis de cambios en las densidades, las villae anteriores al año 1000 tienden a concentrarse entre los 400 y 800 metros de distancia a un curso fluvial, elemento esencial para el desarrollo de la vida rural. En cambio, no parecen buscar tanto la cercanía del mar como lo hacían los asentamientos de época antigua, quizá por motivos de defensa ante las incursiones piráticas normandas o sarracenas.

Mediante la elaboración de polígonos de Thiessen hemos comprobado que el área teórica media de dominio de una villa estaría en torno a los $3,9 \mathrm{~km}^{2}$. Sin embargo, debemos pensar que el territorio medio real de las villae en Nendos debía ser algo inferior, en torno a los 2,0-2,5 km², compensando así los valores altos de las zonas periféricas de este territorio, donde tenemos menos datos de villae. No obstante, sabemos que el tamaño de la villa variaba en cada caso, llegando incluso a los 45 $\mathrm{km}^{2}$ (PALLARES MÉNDEZ; PORTELA SILVA, 1998). Esta red de territorios de villae en Nendos a partir del siglo IX no parece guardar demasiada relación espacial con la red de áreas de castros de época antigua (excepto algunos casos puntuales como por ejemplo Abegondo, donde coinciden en la misma localización, el castro, el asentamiento romano y el hábitat medieval) al contrario de lo que sostienen algunos autores para otras zonas del Noroeste (MARTíN VISO, 2000; LÓPEZ QUIROGA; RODRÍGUEZ LOVELLE, 2000, 2002; GUTIÉRREZ GONZÁLEZ, 1998, 2002). Ya hemos apuntado que el castro mantiene una función de referente espacial en la vida rural alto y plenomedieval y que las villae se hallan en general muy cerca de los anteriores poblamientos en castros, pero parece que al abandonarse el hábitat castreño durante la romanización, desaparecen también las áreas de dominio territorial de cada castro, estableciéndose una nueva organización espacial basada en las comunidades rurales en el valle.

Esta villa que aparece ante nosotros en este periodo, como comentamos anteriormente, es el resultado de una evolución del poblamiento rural desde época tardorromana, y representa una articulación del territorio muy similar a la de la etapa anterior. Por ello, al igual que observábamos para épocas precedentes, las villae se hallan con frecuencia relativamente cerca de un poblamiento castreño y un yacimiento romano, reflejando la idea de continuidad que encontramos constantemente a lo largo de este trabajo. 
Otros elementos presentes en el paisaje medieval de Nendos que dibujan las fuentes documentales son las entidades que hemos llamado "secundarias", es decir: villares, casales, lugares... y demás elementos del territorio humanizado que tanto por su tamaño como por su finalidad no pueden considerarse villae en sí mismas. Sin embargo estas entidades normalmente constituyen parte del territorio de la villa y están relacionadas espacialmente con ella. De hecho, con frecuencia una entidad secundaria como un villar terminará convirtiéndose en una villa. En este periodo no tenemos excesivos datos de entidades secundarias, concretamente 18 entidades anteriores al año 1000. Sin embargo podemos constatar que sus emplazamientos son muy similares a los de las villae, en zonas más bien bajas y llanas, agrícolamente favorables y cercanas a los cursos fluviales, incluso más que los propios núcleos de las villae (posiblemente buscando tierras más fértiles). Normalmente se hallan a menos de 400 metros del núcleo de la villa, y algo más alejadas del centro religioso que dicho núcleo (como se comprueba en las gráficas de densidad según la distancia). Así, podemos considerar sus características espaciales como prolongación de las de la villa. En cambio, sí podría existir una diferencia en cuanto a su cronología y origen, ya que estas entidades secundarias, según ese carácter de dependencia del núcleo aldeano originario, parecen nacer en momentos posteriores a la villa, posiblemente como resultado de una expansión de su poblamiento y sus explotaciones. También podemos pensar que estas entidades secundarias poseerían una tasa de "mortandad" o abandono mayor que las villae, dada su menor importancia a nivel poblacional. Esto parece corroborarse analizando las diversas tasas de pervivencia hasta el día de hoy: las entidades secundarias ofrecen un porcentaje mucho menor (4l\%) de continuidad mínima en la actualidad que las villae (77\%) y las entidades eclesiásticas (87\%).
En cuanto a estas últimas, se trataría tanto de iglesias como de pequeños monasterios, aunque realmente no existe una diferenciación clara entre ambos conceptos durante este periodo. En esta etapa conocemos 18 entidades eclesiásticas mencionadas en la documentación consultada. Como ya hemos comentado, estos centros religiosos parecen jugar un importante papel jerarquizador en el poblamiento y su origen en ocasiones se puede poner en relación con la época tardoantigua (estructuras romanas y necrópolis altomedievales). A la vez, según se observa a través de sus tasas de pervivencia y en el análisis de cercanía a las parroquias actuales, presentan una altísima tasa de continuidad a lo largo del tiempo, ya que en su mayoría estas iglesias se asentaban donde actualmente se emplaza una iglesia parroquial.

Las características espaciales de estas entidades eclesiásticas no parecen diferenciarse del resto de entidades del poblamiento de este periodo: su distribución territorial tiende a la agregación o concentración, la distancia media a la entidad religiosa más próxima oscila entre 1000 y 1500 metros y su emplazamiento suele corresponder a zonas llanas o generalmente no muy elevadas. Esto no debe sorprendernos, pues como observamos en el análisis de distancias, estos centros religiosos se hallan en el propio núcleo de la villa o muy próximos a él (a menos de 200 metros de distancia) ${ }^{12}$ y en 17 de los 18 casos de menciones a entidades eclesiásticas, conocemos también una villa asociada a ella. Todo esto confirma muy claramente el binomio villa-iglesia, es decir, cada villa contaría con una iglesia que forma parte fundamental de la estructura de la aldea, funcionando no solo como centro de culto sino también como cementerio de la comunidad, centro productor (pues sabemos por la documentación que la iglesia tenía sus propias posesiones territoriales), lugar de reunión del concilio de la villa...

12 Al contrario de lo que ocurre en otras regiones de la Península lbérica, en el paisaje rural tradicional de Galicia no es infrecuente que la iglesia parroquial se emplace "aislada" a cierta distancia del núcleo de poblamiento, como también ocurre en Nendos. 
Concluyendo, entre los siglos IX y XI los documentos muestran en Nendos una serie de entidades de poblamiento que no podrían surgir súbitamente en este momento sino que parecen continuar una evolución iniciada en época tardoantigua. Se trata de un poblamiento eminentemente rural basado en una economía agrícola-ganadera, y que parece concentrarse con mayor densidad en la zona central de Nendos. La célula de esta articulación territorial rural es la villa, comunidad agraria con un territorio de explotación delimitado, y en la que se integran otra serie de entidades como los villares, casales, agros... y la iglesia, elemento de referencia y jerarquización fundamental en el paisaje. Toda esta estructura territorial comienza a ser acaparada y controlada en este momento por una serie de poderes feudales que inician ahora una expansión que llegará a su auge en los siglos siguientes.

\section{El territorio de Nendos entre los S. XII-XIII y su continuidad hasta hoy}

La cantidad de entidades de poblamiento conocidas en este periodo es mucho mayor que en épocas precedentes y se distribuye prácticamente por todo el territorio. Podemos considerar que este aumento de las entidades conocidas, a pesar de deberse a un incremento de la documentación escrita producida y conservada, está reflejando también un crecimiento de la población. En los siglos XII y XIII se asiste a una importante expansión demográfica por todo Occidente, que también parece constatarse en nuestro territorio. En primer lugar, los índices de dispersión indican una disminución o suavización del carácter agregado y concentrado del poblamiento en esta etapa. Esto nos informa de la aparición de entidades de poblamiento fuera de los núcleos anteriores, lo que se puede relacionar probablemente con la ocupación y roturación de nuevas tierras. En este sentido, comprobamos que el tipo de entidades que más aparece en estos siglos con respecto al periodo anterior son las entidades secundarias, que aumentan su presencia en un $67,3 \%$ frente al incremento del $60,4 \%$ en las villae y del $41,9 \%$ en el caso de las entidades eclesiásticas.
En esta distribución del poblamiento influye decisivamente, como en etapas anteriores, la cercanía a los cursos de agua y la ocupación de las primeras terrazas fluviales, donde los terrenos de cultivo son más fértiles. En este sentido, el análisis de cambios en las densidades nos informa de que las entidades de poblamiento se ubican a menos de 800 metros de distancia a un curso de agua, siendo las más próximas las entidades secundarias (a menos de 600 metros), ya que su vocación agrícola es más acentuada que el del propio núcleo de la villa. También visualmente comprobamos esta clara tendencia a la disposición de las entidades preferentemente a lo largo de los ríos Mero, Mendo y Mandeo, de forma que el territorio de cada una tiene acceso al río (que generalmente sirve de divisoria espacial) mientras que permanecen menos ocupadas las zonas más alejadas de esta principal red hidrográfica.

Como ya hemos comentado, los siglos XII y XIII representan en el territorio la consolidación espacial del feudalismo. En este sentido, en Nendos contamos con algunos indicios de esta implantación del poder feudal a través de una serie de topónimos con referencias a castillos. De nuevo recalcamos que se trata tan solo de indicios, hipótesis de base meramente toponímica que deben ser consideradas con suma precaución. El emplazamiento concreto de estos topónimos, según las curvas de nivel, se sitúa en zonas relativamente altas, aunque no necesariamente cumbres, sino sobre todo a media altura en laderas, o en la línea de la costa, en lugares con buena visibilidad sobre el litoral y el mar. Estos topónimos sobre castillos se hallan algo más lejos de los cursos fluviales que el resto de entidades, especialmente aquellos situados en la costa. Pero la característica más llamativa de este grupo de topónimos es su distribución totalmente apartada del resto de datos y entidades que estudiamos en este trabajo. Efectivamente esto se comprueba en los análisis de cambios en las densidades, en los que ya observamos como no parece existir relación espacial alguna entre estos topónimos y los castros (al contrario de lo que se podría pensar en un principio), villae, entidades secundarias ni entidades eclesiásticas. 
Su distribución, según los índices de dispersión, apunta a la concentración en zonas determinadas que coinciden aproximadamente con los cuatro extremos de Nendos: al norte, en la zona costera de Sada y Oleiros, al Sur, en el centro del municipio de Cesuras, al Este, en torno al Mandeo y el municipio de Aranga, y al Oeste, entre Abegondo y Carral, zonas todas ellas con menos datos de poblamiento histórico. Tan solo parece existir una relación más o menos indicativa con los restos de época romana, ya que ambas entidades parecen coincidir en su distribución en torno a la costa y a tres ejes horizontales y verticales en los extremos este y oeste de Nendos.

Todo esto parece apoyar la idea de que estos topónimos, o gran parte de ellos, correspondan realmente al emplazamiento de alguna fortificación o estructura defensiva a lo largo de la historia, para control y defensa de zonas limítrofes y costeras. También podemos pensar que la cronología de gran parte de estos posibles castillos se podría encuadrar en el periodo que estamos estudiando, en la etapa de expansión y auge de los poderes feudales que buscarían a través de esta red de fortificaciones asegurar el control y dominio de sus territorios.

La curiosa asociación de estos topónimos sobre castillos con restos de época romana, podría quizá interpretarse en relación con las vías de comunicación. En efecto, los yacimientos romanos, como ya comentamos previamente, se distribuyen con tendencia a la ordenación, concretamente a lo largo de unos ejes verticales y horizontales que unen explotaciones mineras o asentamientos de los siglos II-V d. C. Como hipótesis, esto nos podría estar indicando no solo el aprovechamiento de dichas ubicaciones estratégicas de antiguos yacimientos romanos, sino también la pervivencia de la red viaria de época romana hasta el momento de construcción de las fortificaciones.
Por tanto, entre los siglos XII y XIII nos encontramos ante un territorio aparentemente bien articulado, comunicado y defendido. Sin embargo, al igual que en épocas anteriores, la villa continua siendo, incluso con más claridad, el núcleo básico en la estructuración del territorio. Las características generales de su emplazamiento son las mismas que en la etapa precedente: asentamientos en lugares llanos o de valle, a una distancia de entre 200 y 800 metros a un curso de agua y con una tendencia general a la distribución concentrada en el espacio, aunque de forma más suave que en épocas precedentes. Al igual que en épocas anteriores, la villa aparece siempre en relación con una iglesia, ya que prácticamente la totalidad de las 38 entidades eclesiásticas localizadas con anterioridad a 1250 coinciden con un núcleo de villa, como se puede observar en la figura 2. Como ya hemos comentado anteriormente, las entidades eclesiásticas constituyen las menciones que proporcionalmente menos crecen como primera mención documental entre los siglos XII y XIII, ya que la mayoría de ellas ya habían sido citadas por primera vez entre los siglos IX y Xl. Esto indica que las iglesias y/o monasterios constituyen entidades de gran continuidad temporal, cuyos emplazamientos sufren, por lo general, escasos cambios a lo largo de su historia. Esta continuidad llega hasta nuestros días en la red de parroquias actuales de este territorio. La tasa de pervivencia de las entidades eclesiásticas medievales hasta hoy es altísima, como vimos anteriormente (87\%), ya que en solo 3 casos de los 31 totales no encontramos una iglesia parroquial en el mismo lugar donde se emplazaba la entidad religiosa entre los siglos XII-XIII ${ }^{13}$.

Pero esta continuidad histórica reflejada en las parroquias parece ir más allá. Dada la relación "entidad eclesiástica medieval-parroquia actual" y la asociación "villa-entidad eclesiástica", podemos pensar que también existe una relación entre villa medieval y parroquias actua-

13 Estos lugares: Illobre, Xanrozo, y Xoanzo, constituyen zonas de gran interés para una prospección y excavación arqueológica que localice y estudie aquellas antiguas iglesias, desparecidas también de la memoria popular. 
les. Efectivamente, el mapa de núcleos de villae anteriores a 1250 guarda una enorme similitud con el de parroquias contemporáneas; similitud que se corrobora en el análisis de cambios en las densidades donde se denota una clara relación espacial entre ambas entidades, es decir, una tendencia de las parroquias actuales a continuar el espacio ocupado por la villa medieval. Igualmente, las zonas de mayor densidad de villae hasta 1250 coinciden en gran medida con el área de mayor concentración de parroquias en nuestros días, según se desprende del mapa de interpolación. Pero además, hemos podido constatar una gran aproximación entre las teóricas áreas de dominio de las villae según los polígonos de Thiessen y los límites de las parroquias actuales, que conocemos bien gracias a los trabajos del SITGA. No se trata en absoluto de una coincidencia total (aunque sí lo sea en ciertos casos), pero sí de una clara tendencia de los territorios parroquiales actuales a continuar los probables límites de las villae documentadas entre los siglos IX y XIII. Todo esto nos indica que la iglesia, a lo largo de su proceso de implantación en el territorio durante la Alta Edad Media usaría la villa, que como sabemos, era la unidad esencial de articulación espacial, como base de su presencia a nivel local, creando en ellas iglesias con las que no solo controlaban la vida religiosa de la comunidad rural sino que funcionaban como polo estructurador del poblamiento. Con el tiempo, muchas de estas iglesias en los núcleos de las villae constituirían las parroquias actuales, cuyos límites, consecuentemente, se aproximarían a los de las villae en las que se emplazaban.

Sin embargo, no debemos generalizar estas pautas de evolución, ya que observamos diversos casos en los que dos o incluso más villae dan lugar a una sola parroquia actual. Esto podría deberse a una racionalización de la organización espacial eclesiástica. Como se obser- va en los análisis de dispersión, la red parroquial actual muestra una distribución claramente ordenada y regular, que cubre eficazmente la totalidad del territorio de Nendos, mientras que la distribución de las villae alto y plenomedievales tendía más bien a la concentración en determinadas zonas. Por ello, es posible pensar que en la creación de las estructuras parroquiales se unificasen, por cuestiones de población, distancias u otros factores, zonas con varias entidades de poblamiento bajo una única parroquia. Por otro lado sabemos que las villae son entidades de poblamiento, y por tanto, sujetas a posibles cambios, como su desaparición, su fragmentación en dos (con frecuencia, como hemos visto, a partir de un villar que llega a ser una propia villa), o la integración de dos villae en una. Esto también parece indicar la existencia de una cierta jerarquización de entidades del poblamiento, ya que algunos núcleos llegarán a ser "sedes de parroquia" mientras que otros núcleos poblados se integrarían en el espacio de otra villa y parroquia principal ${ }^{14}$.

Concluyendo, podemos decir que el feudalismo en la etapa final de nuestro estudio sobre el territorio de Nendos consolida y en cierto modo cristaliza para el futuro un proceso de articulación territorial iniciado diez siglos antes. Los poderes señoriales que controlan la producción se hacen patentes físicamente en el paisaje a través de grandes y pequeños centros religiosos que acaparan la renta campesina, así como por medio de una posible red de fortificaciones estratégicamente distribuida por un territorio que ha aumentado sus límites territoriales y posiblemente su poblamiento. Sin embargo, la estructura interna de este territorio continúa siendo la misma de los siglos pasados: una serie de asentamientos rurales en el valle basados en la villa, cuyo territorio de habitación y explotación llegará en muchos casos hasta nuestros días a través de la actual red de parroquias.

\footnotetext{
I4 A este respecto resulta interesante la clasificación tipológica de aldeas gallegas de J. Fariña Tojo, que propone para la zona costera un predominio de las aldeas de un solo núcleo pero poco concentrado, o de varios núcleos dispersos, como parece observarse en Nendos (FARIÑA TOJO, 1980).
} 


\section{CONCLUSIONES}

A lo largo de este trabajo hemos intentado aproximarnos a dos ámbitos poco difusos en la historiografía medieval gallega, como son el estudio territorial desde una perspectiva amplia y diacrónica, y el empleo de Sistemas de Información Geográfica y métodos de análisis espacial. Como se ha podido comprobar, este trabajo adolece de toda una serie de limitaciones que impiden abordar en su totalidad y profundidad estos dos ámbitos. No obstante, sí hemos intentado presentar algunas ideas que consideramos de interés para el estudio del territorio medieval, y extraer ciertas conclusiones acerca de los objetivos que, conscientes de dichas limitaciones, propusimos al comienzo de este trabajo.

El uso de los SIG en el estudio de los territorios, poblamiento y en general cualquier otro ámbito que implique un componente espacial en la Edad Media u otra etapa histórica, constituye una útil y eficaz herramienta. Por un lado, un Sistema de Información Geográfica supone una base o plataforma desde la que desarrollar múltiples estudios, en la que se pueden almacenar, organizar y consultar los datos de las investigaciones y en la que se puede y se debe colaborar en equipo, actualizando, y ampliando constantemente dichos datos. Por otro lado, los SIG permiten transformar, relacionar y adaptar a cada necesidad la información geográfica disponible y sobre todo, crear y producir nuevos datos a partir de ella ${ }^{15}$.

En todas estas posibilidades de los SIG, los métodos de análisis espacial juegan un papel fundamental. Si bien se trata de un ámbito normalmente ajeno a la formación de los historiadores, son justamente ellos quienes deben realizar este tipo de análisis espacial y no el informático o matemático, para comprender adecuadamente cuando y donde es conveniente aplicar estos métodos y cómo se deben interpretar sus resultados. En este trabajo hemos presentado las utilidades de algunos de los métodos más comunes en análisis espacial: cambios de densidades según las distancias a elementos determinados, índices de dispersión que informan sobre el carácter de una distribución, y las distancias medias entre sus miembros, el cálculo de polígonos de Thiessen para reconstruir las áreas teóricas de dominio territorial de una entidad histórica, y los análisis de proximidad o interpolación para crear y combinar mapas de densidades. Todos estos métodos de análisis espacial pueden ofrecer al investigador del territorio una serie de datos importantes e inalcanzables a simple vista sobre la estructura de dicho espacio, de una forma científica y objetiva que permite unificar criterios y comparar con mayor exactitud.

Por todo ello creemos fundamental la combinación e integración de los SIG con métodos de análisis cuantitativo y espacial, superando el mero uso de los SIG como simples contenedores de datos -que lamentablemente tanto abunda en arqueología- y convirtiéndolos en verdaderas herramientas de trabajo en arqueología territorial.

Por otro lado, toda esta metodología no tiene sentido sino es en relación con un mejor conocimiento del mundo medieval. En este sentido, el uso del SIG y los análisis espaciales nos han permitido obtener una serie de datos sobre la evolución histórica del territorio de Nendos que también pueden ser representativos para el estudio del espacio y poblamiento en la Galicia altomedieval ${ }^{16}$. La idea princi-

\footnotetext{
I5 Además de los análisis desarrollados en estas páginas, que suponen tan solo una pequeña parte del enorme potencial de los SIG, citamos como ejemplos de interés en esta temática, la posibilidad de crear ortofotomapas con fotografías aéreas o el desarrollo de modelos digitales del terreno (como el representado en la Figura 10) para el estudio y posible reconstrucción de la viabilidad medieval, la intervisibilidad entre yacimientos, etc.

I 6 No obstante hay que tener en cuenta las diferencias geográficas e históricas entre las diversas comarcas de Galicia. Concretamente el territorio de Nendos posee unas características que lo han convertido en una zona más poblada y dinámica desde la antigüedad y por tanto no todas sus pautas de evolución pueden ser transferidas directamente a otras zonas de Galicia. Por ello se hace necesario un estudio comparativo que permita distinguir rasgos comunes en las estructuras territoriales de la Galicia altomedieval; lo cual constituye uno de los objetivos de la tesis en la que actualmente trabajamos.
} 
pal que parece resumir esta trayectoria temporal ente la Antigüedad y el siglo XIII es la de continuidad, o más bien, cambio en la continuidad. No significa esto que el territorio de Nendos no sufra alteraciones a lo largo del tiempo en su articulación espacial, sino que se trata de cambios progresivos que tienden a adaptarse y mantener unas estructuras más antiguas de organización territorial.

El propio territorio de Nendos constituye ya en sí mismo una muestra de esa continuidad en la organización espacial a lo largo del tiempo. Aunque no se conoce como territorio individualizado hasta mitad del siglo IX, tanto su topónimo de posible sustrato lingüístico prerromano como su clara pertenencia al Ilamado territorio ártabro en época antigua, nos hacen pensar en un origen prerromano para esta división espacial del territorio gallego. Por otro lado sabemos que el territorio de Nendos se convierte en un arciprestazgo de la diócesis de Compostela con el nombre de Nendos, y de esta forma (de nuevo la iglesia como cristalizadora y conservadora en el tiempo largo de estructuras preexistentes) pervive hasta nuestros días. Por tanto, el propio ámbito territorial estudiado muestra, lógicamente con matices, una tendencia a la continuidad en la organización espacial a lo largo de la historia, al menos desde época altomedieval, sino antigua, hasta prácticamente nuestros días.

También la estructura interna de este territorio refleja una alta pervivencia en el tiempo, como en líneas generales proponen otros estudios para el Noroeste hispánico, e incluso para otras muchas zonas de Europa. Esta idea general y matizable de continuidad entre la Antigüedad y Edad Media no es en absoluto novedosa ni revolucionaria (PASTOR DÍAZ DE GARAYO, 1996; NOVO GUISÁN, 1992; MARTÍN VISO, 2000; FERNÁNDEZ MIER 1999a, 1999b) sino que en cierto modo es lo "esperable" si olvidamos las ideas catastrofistas y de cortes bruscos de la historia tradicional, ya que un espacio poblado en general tiende a mantenerse ocupado a lo largo del tiempo, a pesar de, o más bien, con toda una serie de cambios en la cultura, sociedad, política y economía. Más interesante es estudiar el cómo y porqué de esa continuidad, es decir, las características internas de la organización del espacio, las relaciones entre entidades a lo largo del tiempo, las formas del hábitat... En este sentido es importante recordar que el espacio no es simplemente un elemento "pasivo" en la historia, en el que se desarrollan los procesos y acontecimientos temporales, sino que constituye también un agente histórico de primer orden que condiciona e influye en la vida del hombre. Desde esta perspectiva se debe entender el concepto de territorio, es decir, el resultado de una interactuación entre medio físico y humano. Y para comprender dicha interrelación es fundamental adoptar una aproximación diacrónica que analice no un momento histórico incone$x o$, sino la evolución de dicho territorio a lo largo de la historia. Sin embargo, hasta el momento no se han hecho muchos trabajos que revisen desde esta perspectiva territorial amplia y diacrónica el espacio altomedieval en Galicia, que se ha estudiado preferentemente desde la documentación a partir del siglo IX, es decir, en su etapa final, sin retroceder a los datos de época antigua. En este trabajo hemos intentado poner nuestro punto de partida entre los siglos I-V d.C. donde creemos que se sitúa el origen de la comunidad rural y el territorio medieval. Así nos ha parecido observar durante la Alta y Plena Edad Media una continuidad del hábitat y de la organización espacial no tanto desde el castro y su espacio, como algunos autores proponen para otras zonas, (aunque el castro sí siga siendo un elemento de referencia espacial esencial y las villae se sitúen muy cerca de ellos), sino desde los modelos y estructuras de época romana y sobre todo, tardorromana, auténtico origen del territorio medieval, que la iglesia se encargará de desarrollar posteriormente.

Para finalizar, debemos recordar que toda esta búsqueda de datos del pasado no tiene por qué ir siempre lejos en el tiempo ni en el espacio. El paisaje actual sigue conservando muchas e importantes huellas de la organización espacial y en general de los ritmos de la vida en el mundo medieval, aunque cada vez desaparecen más rápido. Se trata de indicios claros y cotidianos, pero a los que nuestros ojos y nuestra mente se han acostumbrado ya 
que muchas veces siguen funcionando en nuestra sociedad. Para descubrirlos solo se precisa una mirada atenta y curiosa porque, a fin de cuentas, el presente es historia viva.

\section{FUENTES DOCUMENTALES}

ANDRADE CERNADAS, José Miguel (1995): O Tombo de Celanova: estudio introductorio, edición e índices (ss. IXXII). Santiago de Compostela.

FERNÁNDEZ DE VIANA Y VIEITES, José Ignacio; GONZÁLEZ BALASCH, María Teresa; CASTRO ÁLVAREZ, Carlos (1999): El monasterio de San Juan de Caaveiro. A Coruña.

LOSCERTALES DE GARCIA DE VALDEAVELLANO, Pilar (1976): Tumbos del monasterio de Sobrado de los Monjes. Madrid.

LUCAS ÁLVAREZ, Manuel (1986): El tumbo de San Julián de Samos (siglos VIII-XII). Santiago de Compostela.

LUCAS ÁLVAREZ, Manuel (1998): Tumbo A de la catedral de Santiago. Santiago de Compostela.

\section{BIBLIOGRAFÍA}

ANDRADE CERNADAS, José Miguel (1996): "Las villae en la Galicia de la mutación feudal: el caso de Celanova", A guerra en Galicia; o rural e o urbano na historia de Galicia. Santiago de Compostela, pp. 277-290.

AZKARATE GARAI-OLAUN, Agustín (1992): "The Western Pyrenees during the Late Antiquity. Reflections for a reconsideration of the issue", II Territorio tra tardoantico e altomedioevo. Metodi di indagine e risultati. Firenze, pp. |79-19|.

BALIÑAS PÉREZ, Carlos (1992): Do mito á realidade: a definición social e territorial de Galicia na Alta Idade Media (seculos VIII e IX). Santiago de Compostela.

BARCELO, Miquel (1998): Arqueología medieval. En las afueras del "medievalismo". Barcelona.

BOUHIER, Abel (200 I): Galicia. Ensaio xeográfico de análisis e interpretación de un vello complexo agrario. Santiago de Compostela.

CAMBI, Franco; TERRENATO, C. (1999): Introduzione all'archeologia dei paessaggi. Roma.

CARBALLO ARCEO, Luis Xulio (1996) "O espacio na cultura castreña galega", A Cultura castrexa galega a debate. Tui, pp. 107-138.
CHAMOSO LAMAS, Manuel (1953): "Hallazgos arqueológicos en Tines ( A Coruña)", Cuadernos de Estudios Gallegos. T. 8. Santiago de Compostela, pp. 15I-I53.

CHAMOSO LAMAS, Manuel (1965): "Sobre las necrópolis paleocristianas últimamente descubiertas en Galicia y Portugal", Anuario de estudios medievais. N. II. Santiago de Compostela, pp. 433-450.

CHAMOSO LAMAS, Manuel (1966): "Noticias arqueológicas de alrededores de La Coruña", Revista / Instituto José Comide de Estudios coruñeses. N. 2. A Coruña, pp. 95- 103.

CHAMOSO LAMAS, Manuel (1967): "Sobre necrópolis de época sueva en Galicia", $I^{a}$ y $2^{a}$ asambleas lusitanogallega. Madrid, pp. 93-96.

CHAMOSO LAMAS, Manuel (197I): "Nuevas noticias sobre necrópolis paleocristianas y germánicas en Galicia", Compostellanum. N. 16, V. I-4. Santiago de Compostela, pp. 20I-2I 2.

CHAMOSO LAMAS, Manuel (1999): "Noticias relativas al hallazgo de necrópolis paleocristianas en las provincias de Pontevedra y A Coruña", Pontevedra en el objetivo de Manuel Chamoso Lamas. Pontevedra, pp. I05- 108.

DEL CASTILLO, Ángel (1923): "Arqueología gallega: sepulturas antropoides", Boletín de la Real Academia Gallega. T. I3, N. | 48, I5I, 152. Santiago de Compostela, pp. 8693, 282-289, 300-309.

ESCALONA MONGE, Julio (1992): "Poblamiento y organización territorial en el sector oriental de la cuenca del Duero en la Alta Edad Media", III Congreso de Arqueología Medieval Española, Oviedo 27 Marzo-I Abril 1989. Oviedo, pp. 448-455.

ESCALONA MONGE, Julio (1994): "Problemas metodológicos en el estudio de los centros de culto como elemento estructural del poblamiento", Burgos en la Plena Edad Media. III Jornadas burgalesas de historia. Burgos, pp. 573-598.

ESCALONA, J.; ALFONSO, I.; REYES, F. (en prensa): "Espacios con memoria. Apuntes para una agenda de investigación sobre el paisaje medieval".

FARIÑA BUSTO, Francisco.; SUÁREZ OTERO, José. (1997): "As necrópoles xermano-suévicas", Galicia castrexa e romana. Santiago de Compostela, pp. 304-3I2.

FARIÑA JAMARDO, Xosé (1996): La parroquia rural en Galicia. Santiago de Compostela.

FARIÑA TOJO, José (1980): Los asentamientos rurales en Galicia. Madrid.

FERNÁNDEZ MIER, Margarita (1999): "El origen de la "villa" medieval y la progresiva configuración del espacio agrario", II Congreso de Arqueología Peninsular. Madrid, pp. 475-484.

FERNÁNDEZ MIER, Margarita (1999): Génesis del territorio en la Edad Media. Arqueología del paisaje y evolución histórica en la montaña asturiana. Oviedo. 
FRANCOVICH, Riccardo (1987): Archeologia e Storia del Medioevo italiano. Roma.

GUTIÉRREZ GONZÁLEZ, José Avelino (1998): "Sobre los orígenes de la sociedad asturleonesa: aportaciones desde la arqueología del territorio", Studia historica. Historia medieval. N. 16. Salamanca, pp. 13-43.

GUTIÉRREZ GONZÁLEZ, José Avelino (2002): “Del Castrum al Castellum. Los castros entre la Antigüedad y la Edad Media", Los poblados fortificados del noroeste de la Península Ibérica: formación y desarrollo de la cultura castreña: coloquios de arqueología en la cuenca del Navia: homenaje al Profesor Dr. José Manuel González y Fernández-Vallés. Navia, pp. 301-316

HODDER, lan; ORTON, Clive (1990): Análisis espacial en arqueología. Barcelona.

ISLA FREZ, Amancio (1998): "Aspectos de la organización del espacio en Galicia: El alto Tambre, siglo IX-XI", "L'incastellamento". Actes des Rencontres de Gérone (2627 Novembre 1992) et de Rome (5-7 Mai 1994). Roma, pp. 57-70.

ISLA FREZ, Amancio (200 I): "Villa, villula, castellum. Problemas de terminología rural en época visigoda", Arqueología y territorio medieval. N. 8. Jaén, pp. 9-20,

LA ROCCA HUDSON, Cristina; HUDSON, Peter J. (1987): "Riflessi della migrazione longobarda sull'insediamento rurale urbano in Italia settentrionale", Archeologia e Storia del Medioevo italiano. Roma, pp. 29-47.

LÓPEZ ALSINA, Fernando (1988): La ciudad de Santiago en la Alta Edad Media. Santiago de Compostela.

LÓPEZ QUIROGA, Jorge (2002): "Fluctuaciones del poblamiento y hábitat "fortificado" de altura en el noroeste de la Península Ibérica (siglos V-IX)", Mil anos de fortificaçoes na Península e no Magreb (500-1500): actas do Simposio Internacional sobre Castelos. Lisboa, pp. 83-91.

LÓPEZ QUIROGA, Jorge; RODRÍGUEZ LOVELLE, Mónica (2000): "El poblamiento rural en torno a Lugo en la transición de la Antigüedad al feudalismo (ss. V-X)", Cuadernos de estudios gallegos. XLVII, fasc. I 13. Santiago de Compostela, pp. 53-76.

LUENGO MARTÍNEZ, José (1950): "Exploraciones en el castillo de Aranga", Cuadernos de Estudios Gallegos. N. VI. Santiago de Compostela, pp. 21-35.

MACCHI JÁNICA, Giancarlo (200I): "Sulla misurazione delle forme d'occupazione sociale dello spazio medievale", Archeologia Medievale. XXVIII. Firenze, pp. 6I-82.

MARTÍN VISO, Iñaki (2000): Poblamiento y estructuras sociales en el Norte de la Península Ibérica. Siglos VI-XIII. Salamanca.

MORALEJO LASSO, Abelardo (1977): Toponimia gallega y leonesa. Santiago de Compostela.

NAVEIRO LÓPEZ, Juán L. (1994): El Golfo Ártabro. Arqueología e historia del gran puerto de los galaicos lucenses. A Coruña.
NOVO GUISÁN, José Miguel (1992): Los pueblos vascoscantábricos y galaicos en la antigüedad tardía: siglos III-IX. Alcalá de Henares.

NUÑEZ RODRIGUEZ, Manuel (1977a): "Algunas inscripciones de la Galicia prerrománica", Boletín Auriense. T. 7. Ourense, pp. 173-194.

NUÑEZ RODRIGUEZ, Manuel (1977b): "Enterramientos y sarcófagos de la Galicia prerrománica", Archivos leoneses. N. 62. León, pp. 359-379.

PALLARES MÉNDEZ, Maria del Carmen (1979): El Monasterio de Sobrado: un ejemplo del protagonismo monástico en la Galicia medieval. La Coruña.

PALLARES MÉNDEZ, María del Carmen.; PUENTE MíGUEZ, J. A. (|98I): "Villa Bidualdi. Un despoblado del siglo X. Aproximación arqueológica", Cuadernos de Estudios Gallegos. N. XXXII. Santiago de Compostela, pp. 475-486.

PALLARES MÉNDEZ, María del Carmen; PORTELA SILVA, Ermelindo (1997): "Galicia á marxe do Islam. Continuidade das estructuras organizativas no tránsito á ldade Media", Galicia fai dous mil anos. O feito diferencial galego. I. Historia. Santiago de Compostela, pp. 435-458.

PALLARES MÉNDEZ, María del Carmen; PORTELA SILVA, Ermelindo (1998): "La villa por dentro. Testimonios galaicos de los siglos $X$ y Xl", Studia histórica. Historia medieval. N. 16. Salamanca, pp. 13-43.

PASTOR DÍAZ DE GARAYO, Ernesto (1996): Castilla en el tránsito de la Antigüedad al Feudalismo. Valladolid.

PÉREZ LOSADA, Fermín (1995): "Arqueoloxía e Arte no mundo rural: hábitat e arquitectura das villae galaicorromanas", Arqueoloxía e Arte na Galicia Prehistórica e Romana. Museo Arqueolóxico e Histórico da Coruña, Monografías. N. 7. A Coruña, pp. 165-188.

PÉREZ LOSADA, Fermín (2002): Entre a cidade e a aldea. Estudio arqueo-histórico dos "aglomerados secundarios" romanos en Galicia. La Coruña.

PORTELA SILVA, Ermelindo (2002): "Galicia y los reyes de Oviedo", La época de la monarquía asturiana. Oviedo, pp. 35।-365.

PRECEDO LEDO, Andrés; GALLEGO PRIEGO, M. (200I): Mapa de límites das parroquias: cartografia territorial básica de Galicia. Santiago de Compostela.

QUIRÓS CASTILLO, Juán Antonio (2003): “La llanada oriental entre la tardoantigüedad y el año mil: las transformaciones en la estructura del hábitat y del poblamiento rural", La llanada oriental a través de la historia: claves desde el presente para comprender nuestro pasado. Vitoria, pp. 43-5I.

RIPOLL, Gisela; ARCE, Javier (200 I): "Transformación y final de las villae en occidente (siglos IV-VIII): problemas y perspectivas", Arqueología y territorio medieval. N. 8. Jaén, pp. 21-53. 
RODRÍGUEZ CAMPOS, Xoaquín (|99|): "A organización social e o territorio na Galicia tradicional: aldeas, parroquías e concellos", Galicia. Antropoloxía. La Coruña, pp. I58-199.

SÁNCHEZ ALBORNOZ, Claudio (198|): Estudios sobre Galicia en la temprana Edad Media. La Coruña.
VALDÉS BLANCO-RAJOY, Rosario (1996): "I campaña de excavación arqueolóxica en San Xoan de Caaveiro", Cátedra. Revista Eumesa de estudios. N. 3. Pontedeume (La Coruña), pp. 213-242.

W.AA. (1998): Enciclopedia temática de Galicia. Historia. Barcelona. 


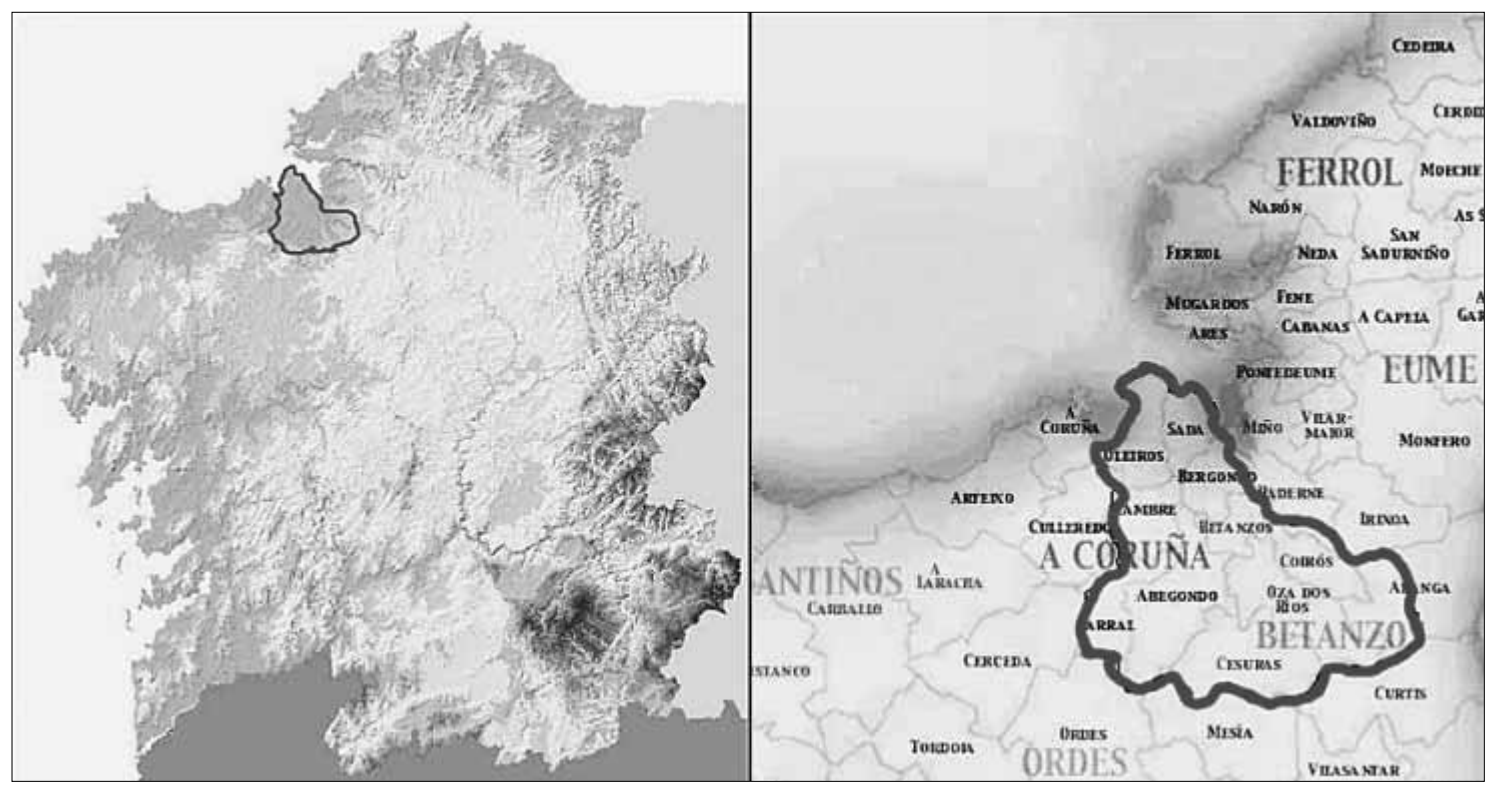

Fig. I. Límites aproximados del territorio de Nendos (en torno al siglo XII) en Galicia y en la actual provincia coruñesa.

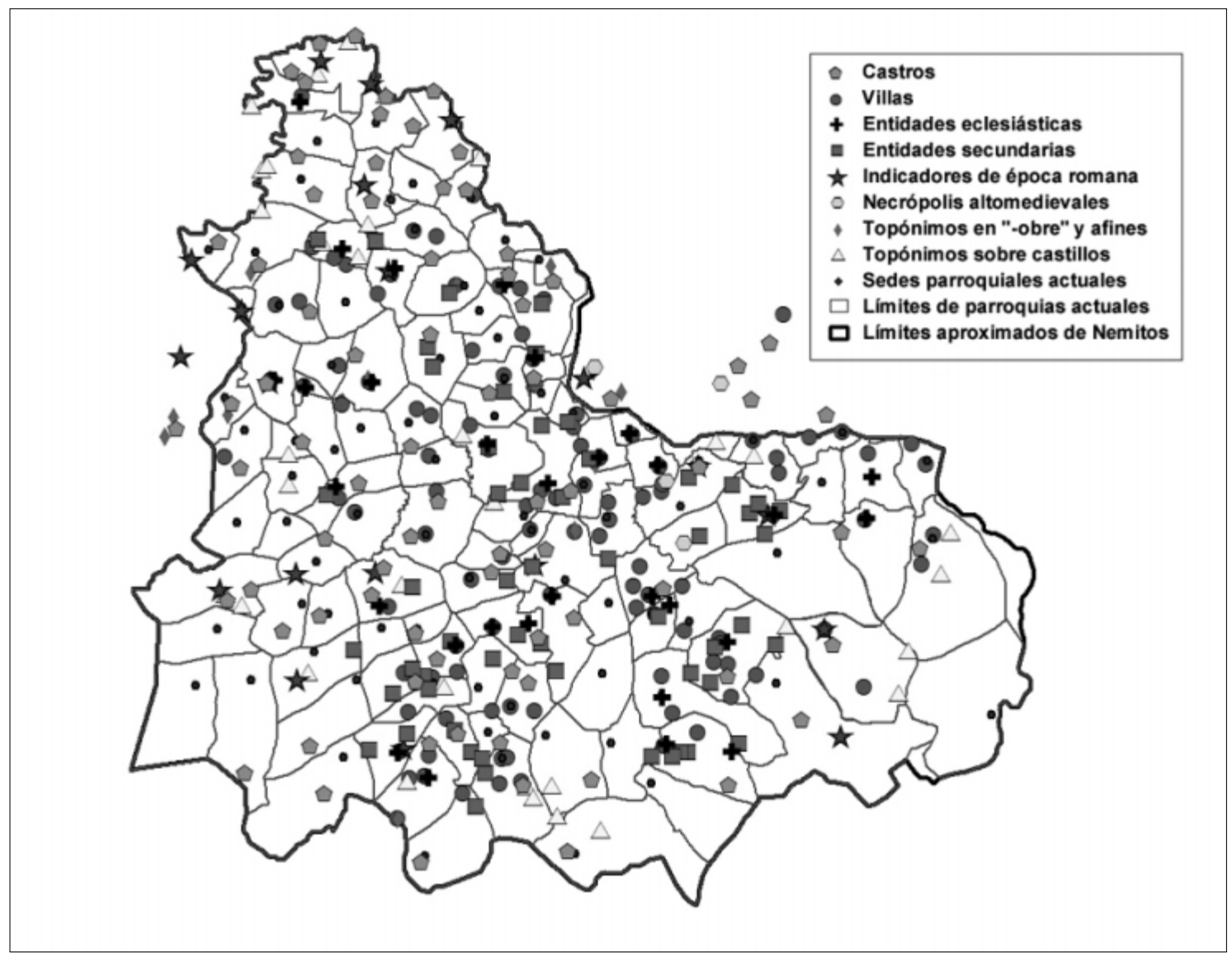

Fig. 2. Datos recopilados en la reconstrucción de la red de poblamiento del territorio de Nemitos o Nendos entre la Antigüedad y la Plena Edad Media. 


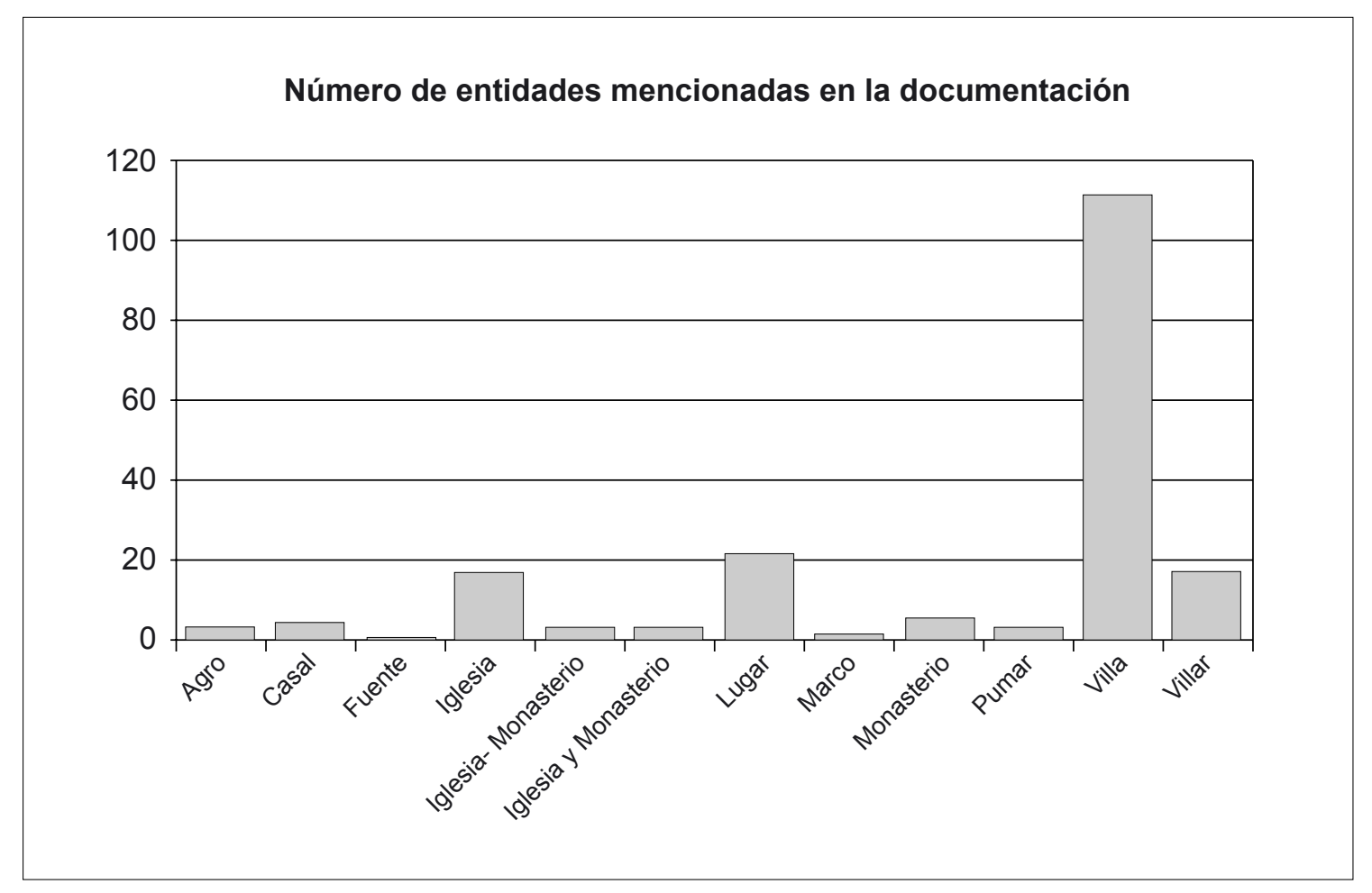

Fig. 3. Tipo y número de menciones documentales relacionadas con el poblamiento medieval (ss. IX-XIII) en el territorio de Nendos.

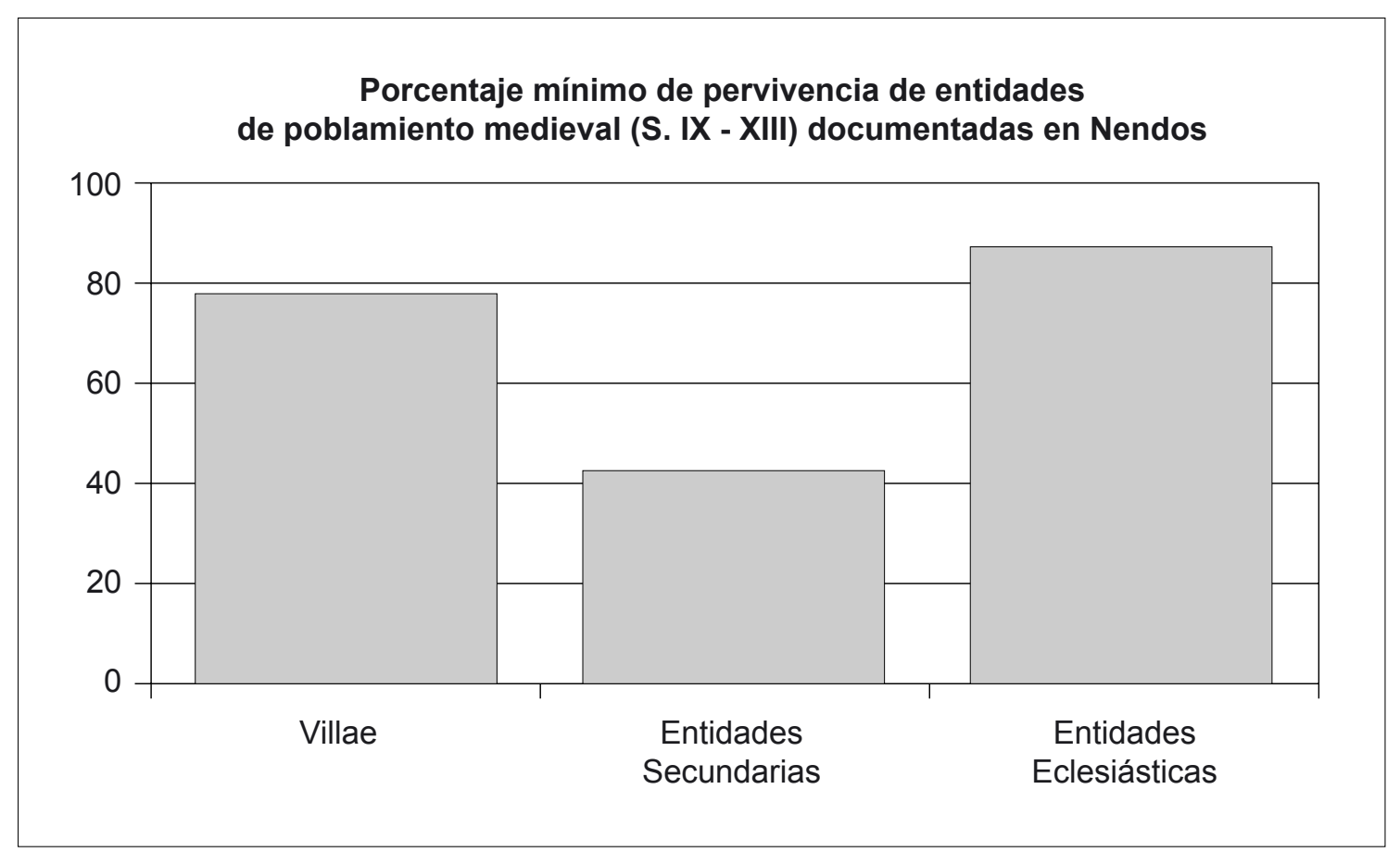

Fig. 4. Tasa de continuidad con certeza hasta la actualidad de los tres tipos de entidades de poblamiento entre los siglos IX y XIII en Nendos. 
SAU QUADRAT

Date: mar, 08 de Jul de 2003

Time: 18:05:43

Path: C:ITrabajoslCastros en Nemitos.txt

N. points: 72

Selection: no

Mask: yes

Masked: yes - 49

Quadrats: $11 \times 11$

\# quadrats: 72

Quadrat area: 7728400 sqr. units

Total area: $9.351364 \mathrm{e}+08$

Optimal quadrat area: 7728400

Optimal quadrat size: 2780

Statistics:

g2 $=0,764$

mean $=0,972$

g2mean $=0,786$

Histogram:

$0: 23$

1: 32

2: 13

3: 4

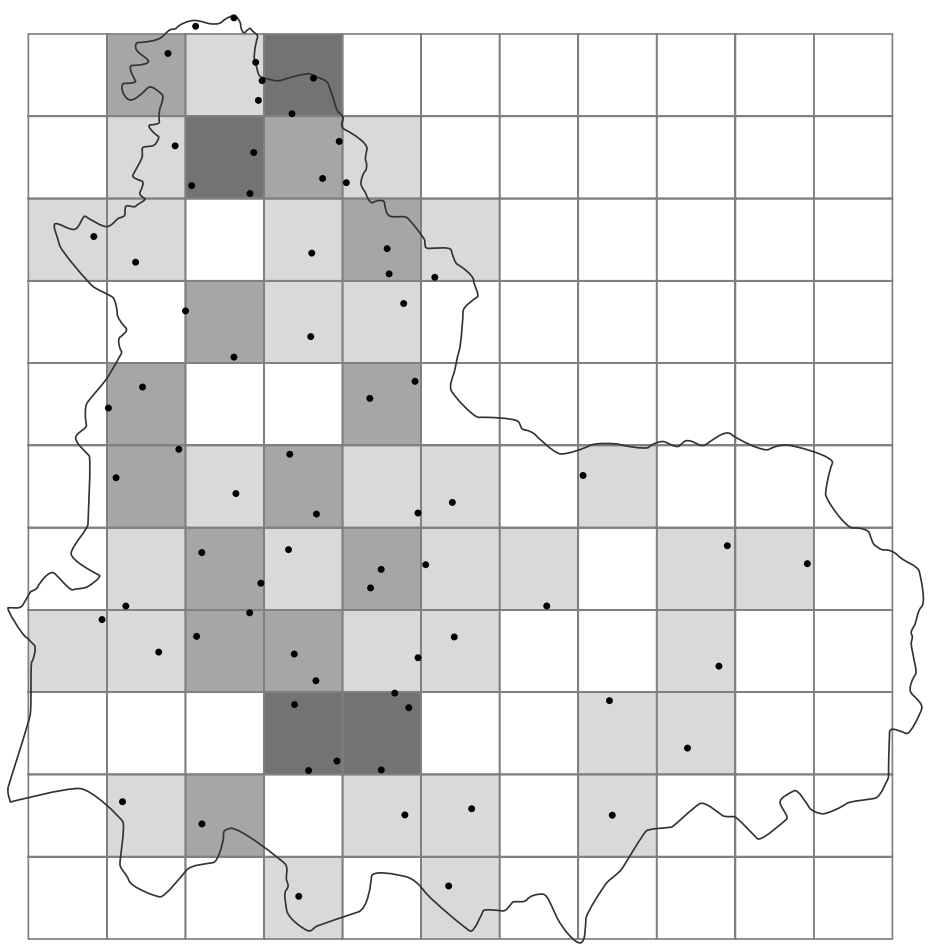

Fig. 5. Análisis de distribución de castros en Nendos mediante método de cuadrados con SAU.

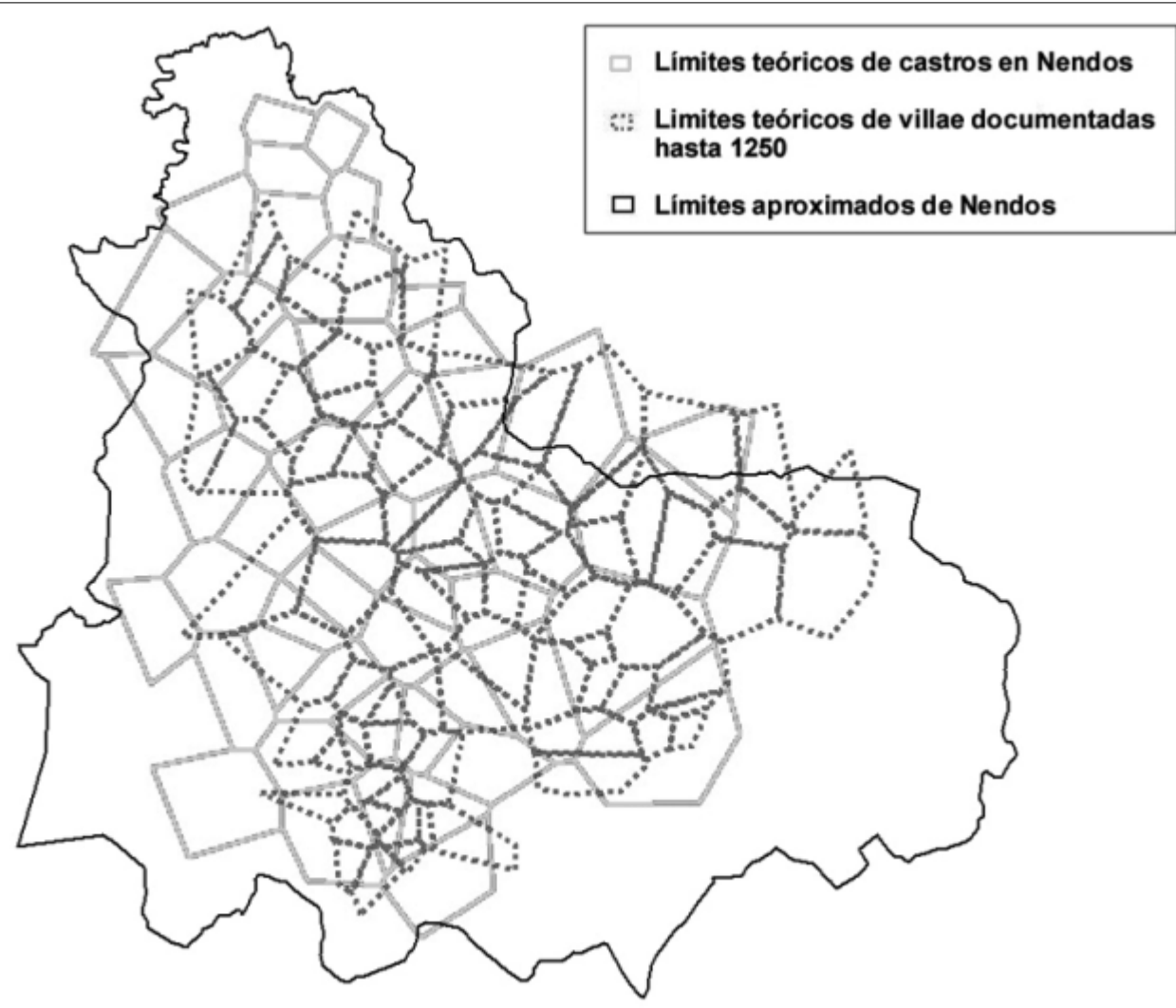

Fig. 6. Comparación entre polígonos Thiessen de la red de castros y villae documentadas hasta 1250 en el territorio de Nendos. 


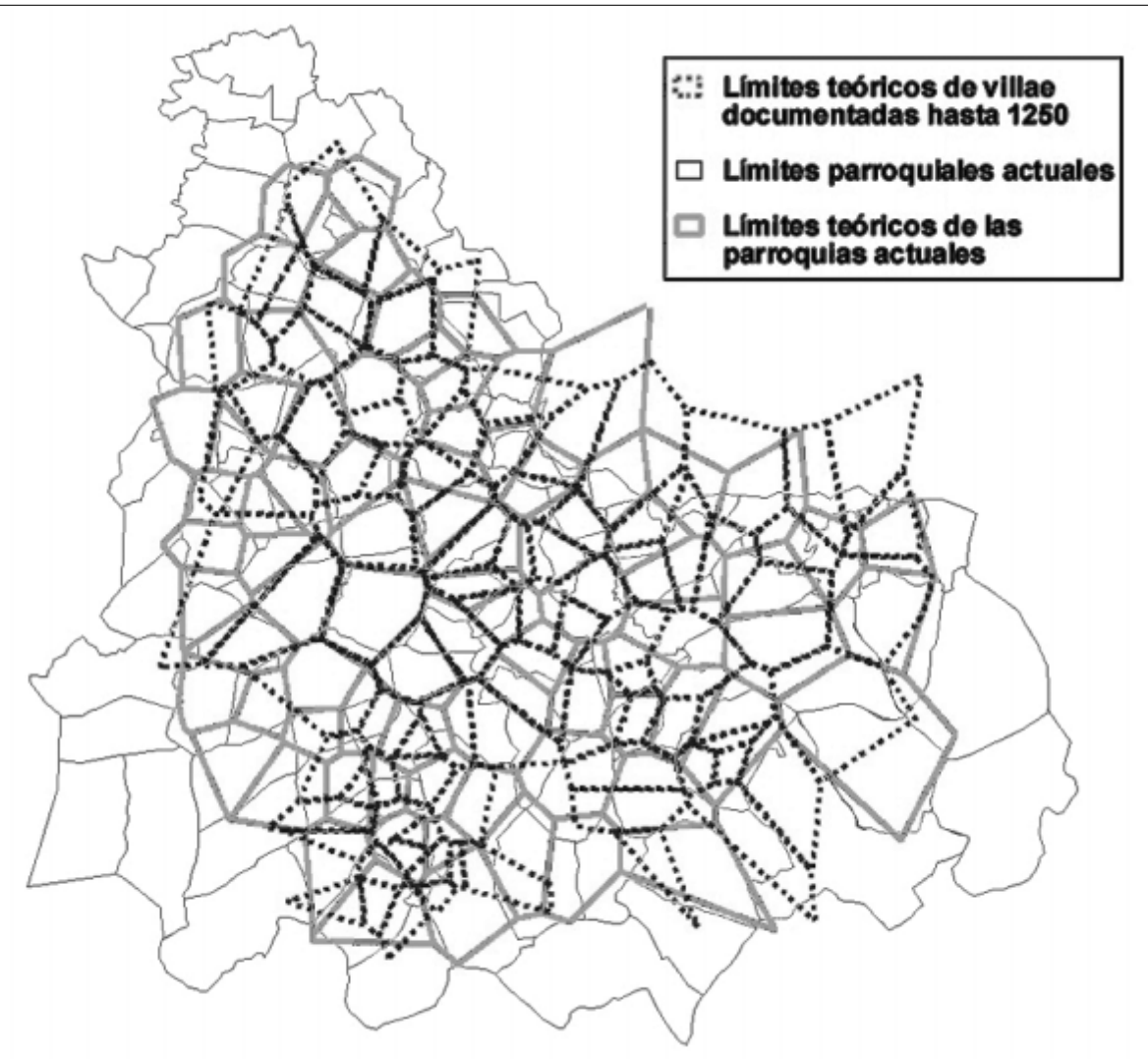

Fig. 7. Comparación entre polígonos Thiessen de las villae documentadas hasta mitad del siglo XIII y los límites parroquiales actuales (reales y teóricos) en el territorio de Nendos.

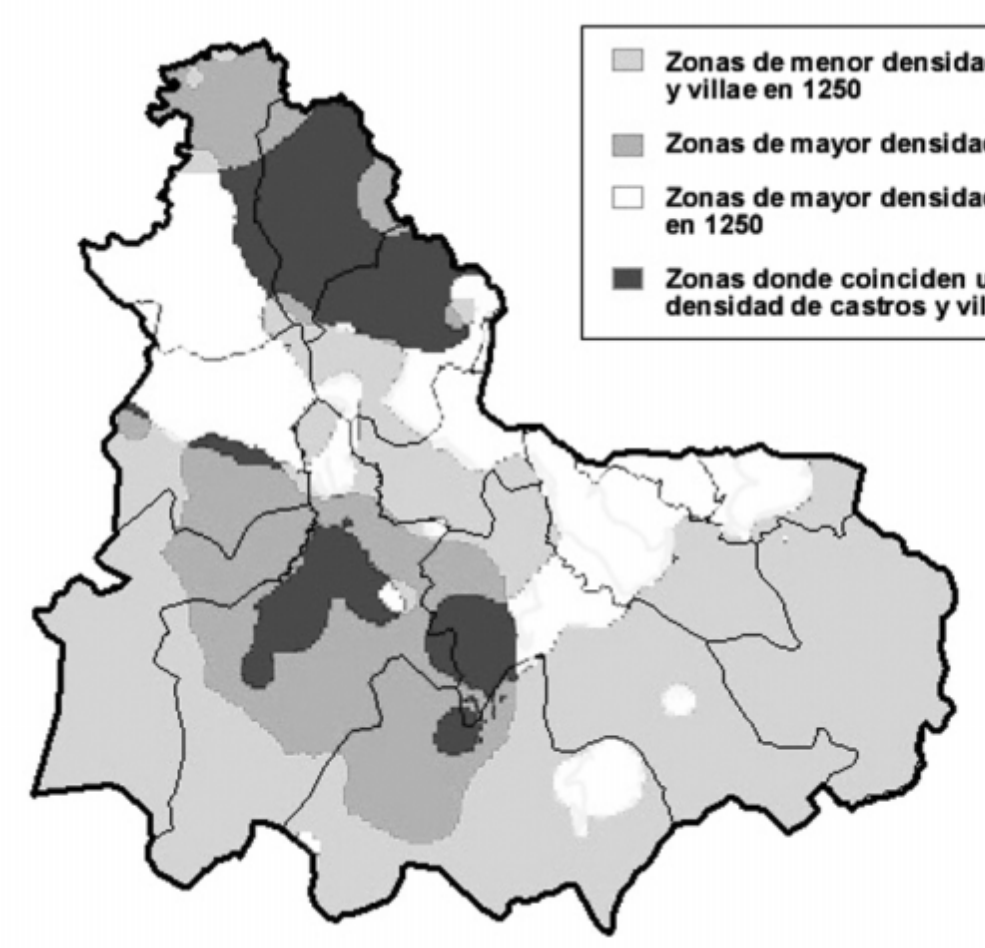

Fig. 8. Superficie de interpolación para representar áreas de densidad de castros y de villae en 1250. 


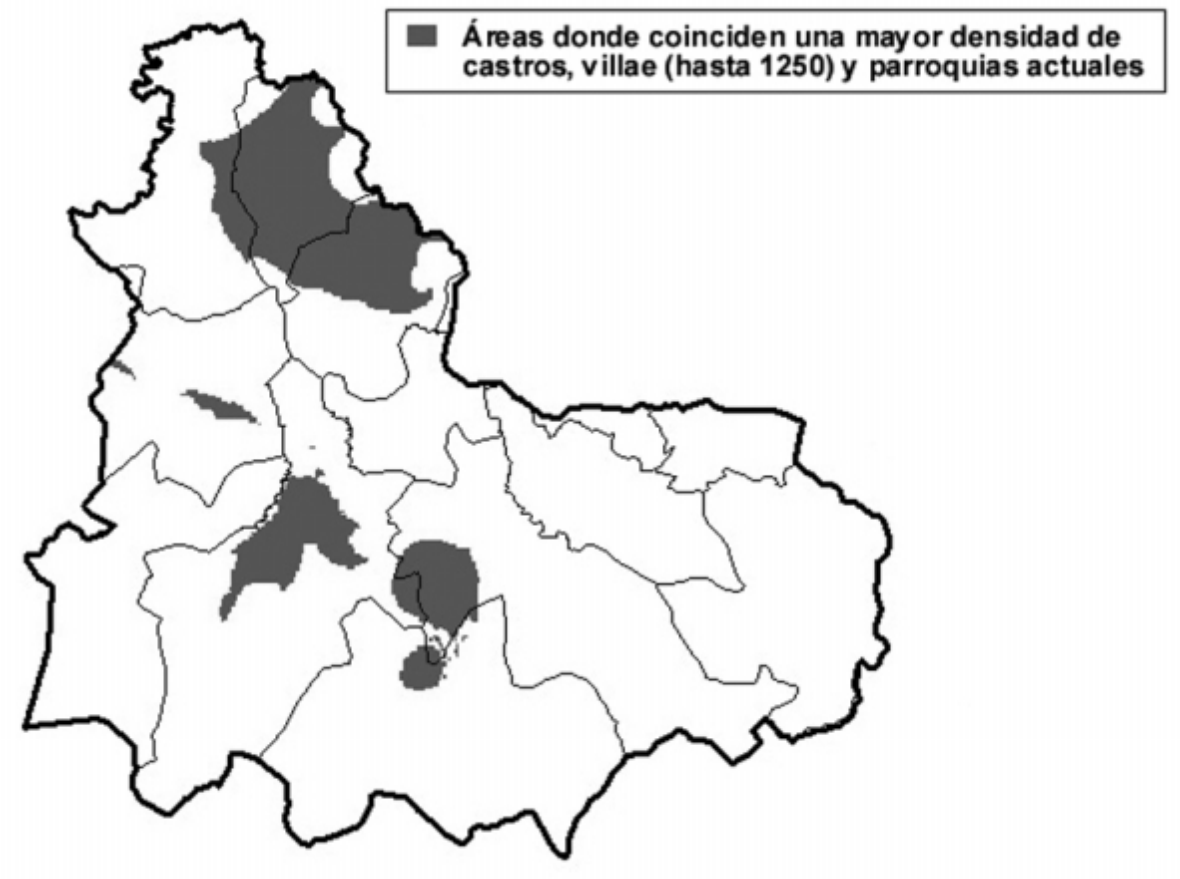

Fig. 9. La suma de diversos mapas de interpolación da como resultado las áreas de coincidencia de mayor densidad de castros, villae (hasta mitad del siglo XIII) y parroquias actuales. Son las zonas más pobladas y con más clara continuidad histórica en este territorio a lo largo de los últimos veinte siglos.

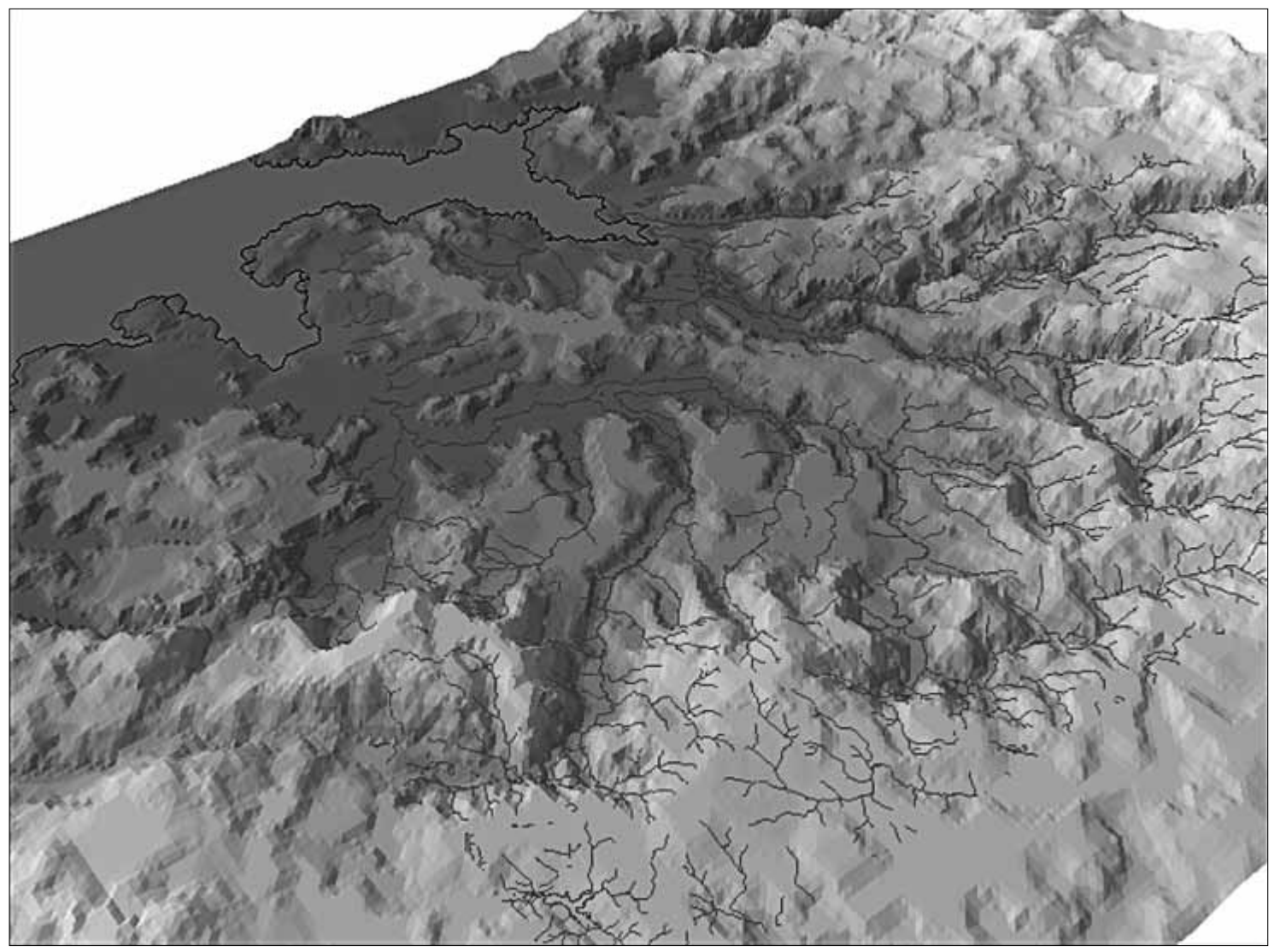

Fig. I M. Modelo digital del terreno (DTM) del territorio de estudio. 


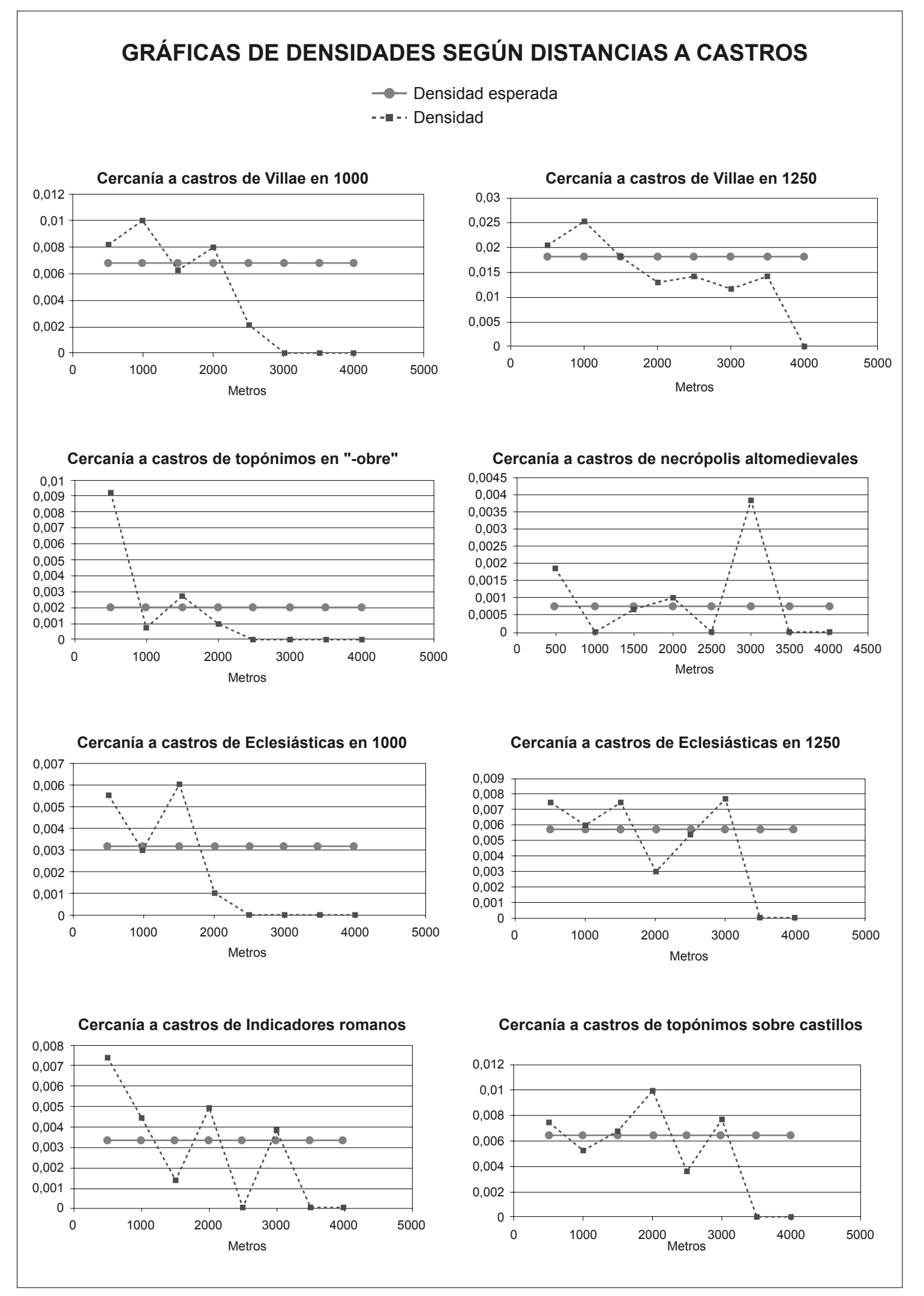

Fig. I I. Cambios en las densidades de distintas entidades de poblamiento histórico del territorio de Nendos según su distancia a la red de castros. 


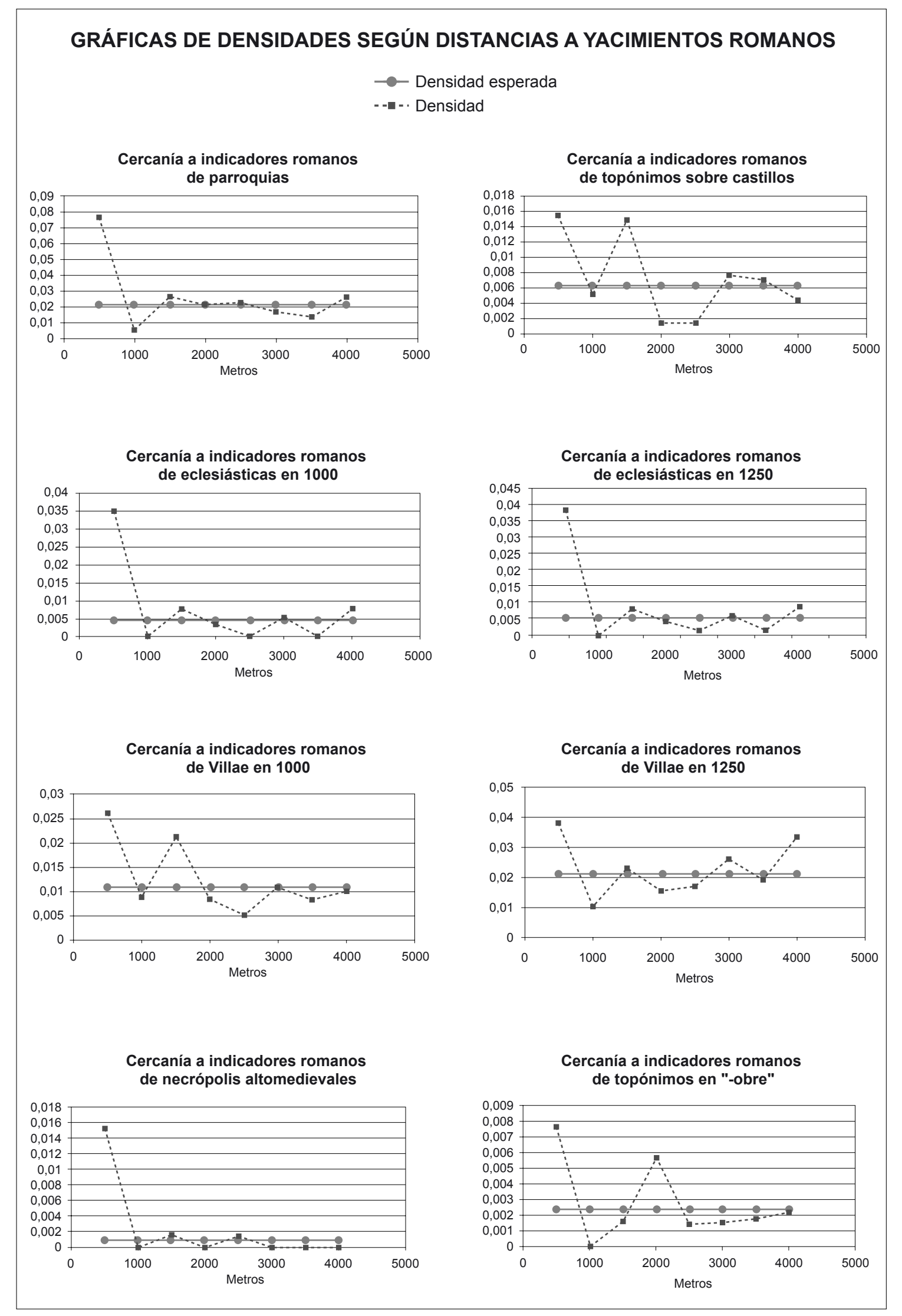

Fig. I2. Cambios en las densidades de distintas entidades de poblamiento histórico del territorio de Nendos según su distancia a yacimientos indicadores de cultura galaicorromana. 


\section{GRÁFICAS DE DENSIDADES SEGÚN DISTANCIAS A LA RED HIDROGRÁFICA}

- - Densidad esperada

- - - - Densidad
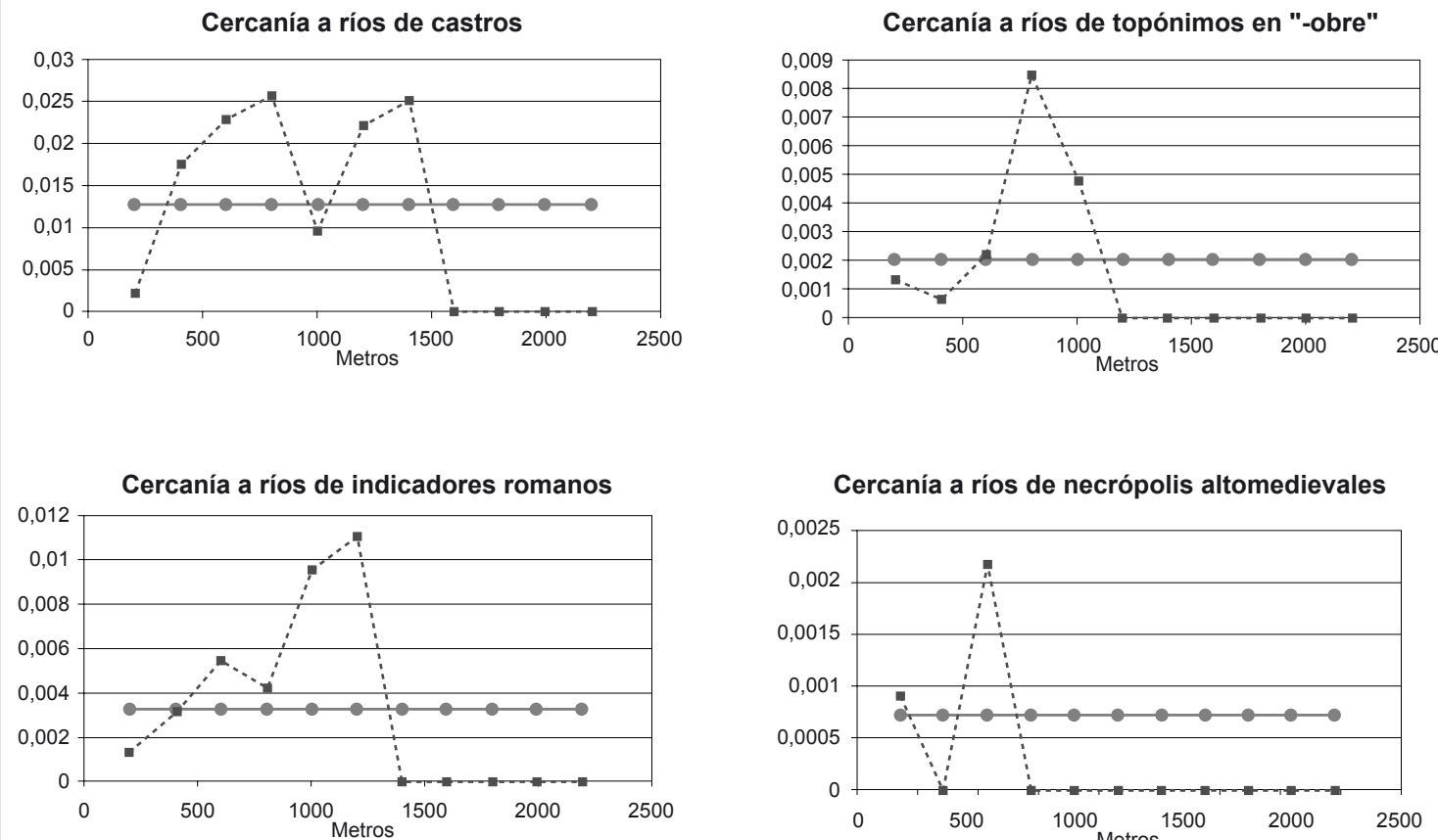

\section{Cercanía a ríos de necrópolis altomedievales}

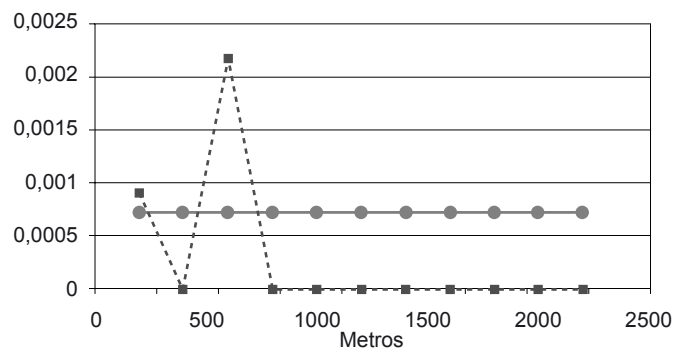

Cercanía a ríosde Villae en 1000

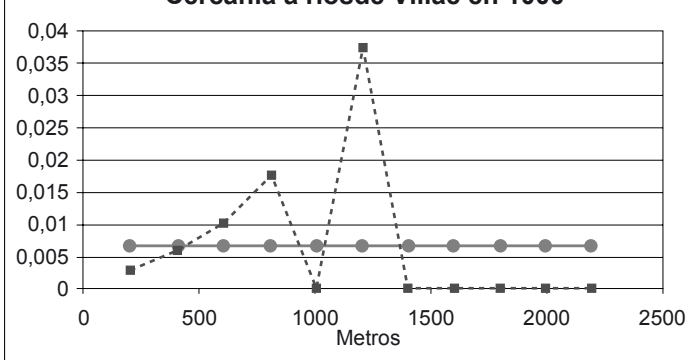

Cercanía a ríos de Villae en 1250

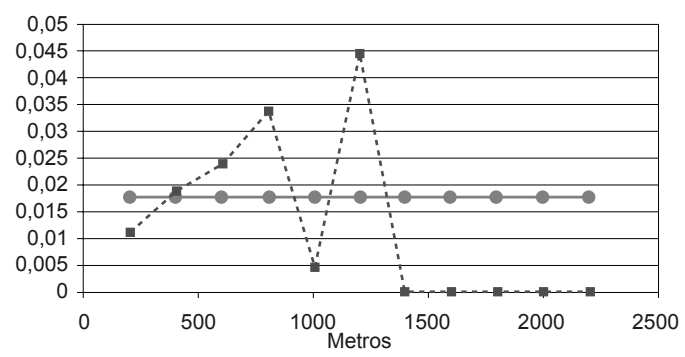

Cercanía a ríos de eclesiásticas en 1250

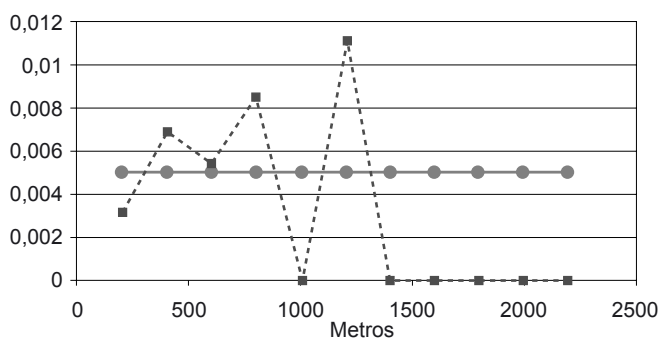

Cercanía a ríos de topónimos sobre castillos

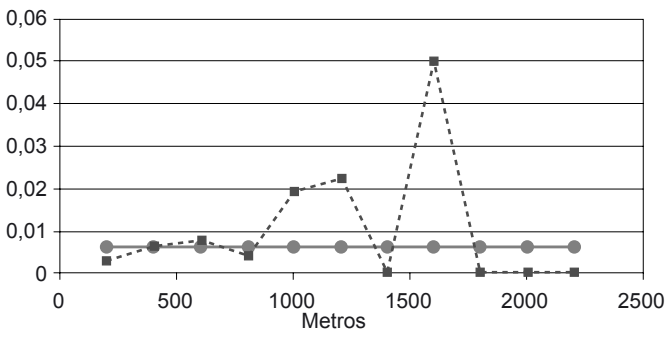

Fig. I3. Cambios en las densidades de distintas entidades de poblamiento histórico del territorio de Nendos según su distancia a la red hidrográfica. 